\title{
Small molecule inhibitors of RAS-effector protein interactions derived using an intracellular antibody fragment
}

Camilo E. Quevedo', Abimael Cruz-Migoni (10 1,2, Nicolas Bery¹, Ami Miller¹, Tomoyuki Tanaka ${ }^{3,8}$, Donna Petch ${ }^{3}$, Carole J.R. Bataille ${ }^{4}$, Lydia Y.W. Lee ${ }^{5}$, Phillip S. Fallon ${ }^{5}$, Hanna Tulminn,9, Matthias T. Ehebauer ${ }^{1,10,}$ Narcis Fernandez-Fuentes (1) 2,6, Angela J. Russell4, Stephen B. Carr ${ }^{2,7}$, Simon E.V. Phillips (1) ${ }^{2,7}$ \&

Terence H. Rabbitts ${ }^{1}$

Targeting specific protein-protein interactions (PPIs) is an attractive concept for drug development, but hard to implement since intracellular antibodies do not penetrate cells and most small-molecule drugs are considered unsuitable for PPI inhibition. A potential solution to these problems is to select intracellular antibody fragments to block PPIs, use these antibody fragments for target validation in disease models and finally derive small molecules overlapping the antibody-binding site. Here, we explore this strategy using an anti-mutant RAS antibody fragment as a competitor in a small-molecule library screen for identifying RAS-binding compounds. The initial hits are optimized by structure-based design, resulting in potent RAS-binding compounds that interact with RAS inside the cells, prevent RAS-effector interactions and inhibit endogenous RAS-dependent signalling. Our results may aid RASdependent cancer drug development and demonstrate a general concept for developing small compounds to replace intracellular antibody fragments, enabling rational drug development to target validated PPIs.

\footnotetext{
${ }^{1}$ Weatherall Institute of Molecular Medicine, MRC Molecular Haematology Unit, University of Oxford, John Radcliffe Hospital, Oxford OX3 9DS, UK.

${ }^{2}$ Research Complex at Harwell, Rutherford Appleton Laboratory, Didcot, Oxon OX11 OFA, UK. ${ }^{3}$ Leeds Institute for Molecular Medicine, St James University Hospital, Leeds LS9 7TF, UK. ${ }^{4}$ Chemistry Research Laboratory, 12 Mansfield Rd, Oxford OX1 3TA, UK. ${ }^{5}$ Domainex, Chesterford Research Park, Little Chesterford, Saffron Walden CB10 1XL, UK. ${ }^{6}$ Institute of Biological, Environmental and Rural Sciences, University of Aberystwyth, Aberystwyth SY23 3 EB, UK. ${ }^{7}$ Department of Biochemistry, University of Oxford, South Parks Road, Oxford OX1 3QU, UK. ${ }^{8}$ Present address: Research \& Development, Sanofi K.K. Tokyo Opera City Tower, 3-20-2, Nishi Shinjuku, Shinjuku-ku, Tokyo 163-1488, Japan. ${ }^{9}$ Present address: Wellcome Trust Centre for Human Genetics, Roosevelt Drive, Oxford OX3 7BN, UK. ${ }^{10}$ Present address: Oxford Drug Discovery Institute, Nuffield Department of Medicine Research Building, University of Oxford, Old Road Campus, Oxford OX3 7FZ, UK. These authors contributed equally: Camilo E. Quevedo, Abimael Cruz-Migoni. Correspondence and requests for materials should be addressed to T.H.R. (email: terence.rabbitts@imm.ox.ac.uk)
} 
$\mathrm{T}$ here are at least two problem areas in devising therapeutics to intracellular targets in disease. Most are not enzymes per se for which active site inhibitors can be derived, but rather their function is mediated by specific protein-protein interactions (PPIs $)^{1}$. This has led to the development of macromolecules like intracellular antibody fragments ${ }^{2-4}$ (herein referred to as macrodrugs, distinct from conventional drugs $)^{5}$ that fold and interact with targets in the intracellular environment and can blockade PPI due to higher relative affinity scores compared with natural PPI partner6. Thus intracellular antibodies or peptide aptamers ${ }^{7}$ can easily be selected with high affinity and be used for target validation by interrogating relevant preclinical models for effects on the specific disease, such as a mutant RAS in cancer ${ }^{3}$. However, devising methods to internalize these macrodrugs into cells to achieve the function has been elusive. Small-molecule drugs have opposite innate properties to macrodrugs. They can readily penetrate cells, but they are thought to lack the ability to interfere with PPIs because of low affinity and low surface area interaction $^{8-10}$, although examples of compounds with effects against PPI have been described in recent years ${ }^{11,12}$. One way to bring together these various properties is to use macrodrugs that have been used for target validation to select small compounds that bind to the target at the same location and which would thus have the potential for hit to lead drug development (macrodrugs include a variety of macromolecules, ranging for instance from oligonucleotides, to mRNA to proteins). Human intracellular single-domain antibody fragments have been well characterised since the first example ${ }^{13}$. The binding site of a variable region domain comprises about $600 \AA^{2} 14$ and is the minimal region of an antibody-binding site recognizing an antigen ${ }^{15}$. This is a very small region equivalent to less than 500 daltons $^{16}$ and can narrow down the protein target area in competition screenings. Searching in smaller areas will increase the chances of detecting small molecules (within the Lipinski rules ${ }^{17}$ ) with similar properties as the previously validated antibody fragments.

The RAS family of proteins is among the most frequently mutated in human cancers ${ }^{18,19}$, with KRAS mutations found in almost all pancreatic tumours, about $40 \%$ of colorectal tumours and about $30 \%$ of lung adenocarcinomas ${ }^{20} \mathrm{http}: / /$ cancer.sanger. ac.uk/cosmic. Reagents that block these RAS-effector interactions have thus far largely been macromolecules ranging from cyclic peptides $^{21}$ to antibodies ${ }^{22,23}$ or antibody fragments ${ }^{3,4}$ and, from a number of approaches targeting the RAS family of proteins with small compounds ${ }^{24-32}$, only two have shown direct RAS-effector interface inhibition ${ }^{31,32}$. We have characterized an antibody fragment, using intracellular antibody capture technology $y^{33,34}$, that specifically binds to the activated forms of HRAS, KRAS and NRAS with optimal binding properties (low Kd, high $K_{\text {on }}$ and low $\left.K_{\text {off }}\right)$ and inhibits tumour growth in xenograft models ${ }^{35}$ even when mutations in other proteins are present in the cells ${ }^{3}$. Crystallisation with the antibody fragment yielded an $\mathrm{scFv}$ HRAS $^{\mathrm{G} 12 \mathrm{~V}}$ crystal complex, where the binding site of the antibody fragment was identified and its RAS-effector inhibitory properties were understood ${ }^{36}$.

Here, we employ the intracellular antibody to identify a compound from a chemical fragment library that binds to RAS proteins adjacent to the effector binding region. High-resolution crystal structures show the binding of this compound to mutant RAS, and this structural information facilitates hit to lead development. Our structure-based approach has produced compounds that bind to mutant KRAS with sub- $\mu \mathrm{M}$ affinity that interfere with RAS-effector PPI and endogenous RAS-dependent signalling in human cancer cells, and show a correlation between in vitro binding and potency in the cells. Our work demonstrates that intracellular antibody fragments can be used as progenitors in drug development programmes to arrive at high-affinity compounds binding to mutant KRAS. This approach can be generalised to any PPI in a disease.

\section{Results}

SPR with anti-RAS antibody identifies RAS-binding compounds. The initial SPR screening strategy is outlined in Fig. 1a-c, in which compounds from a fragment-based, small-molecule library were counter-screened for the binding to GTP-bound (Fig. 1a) or GDP-bound (Fig. 1b) HRAS. The chemical fragment library, comprising 656 compounds, was screened using a BIAcore T100 with single-point analysis of each compound at $200 \mu \mathrm{M}$ (Fig. 1d). Putative RAS-binding compounds were individually retested using GST-HRAS ${ }^{\mathrm{G} 12 \mathrm{~V}}$-GTP $\gamma \mathrm{S}$ and wild-type GST-HRASGDP. One compound, out of 26 initial hits, with a quinoline core (Abd-1) showed preferential binding to $\mathrm{HRAS}^{\mathrm{G} 12 \mathrm{~V}}-\mathrm{GTP} \gamma \mathrm{S}$ (Fig. 1e, g). The dose response of Abd-1 (3 to $2000 \mu \mathrm{M}$ range) was

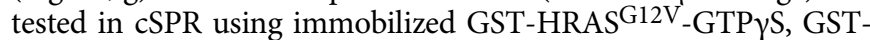

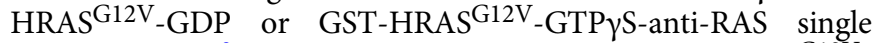
chain Fv (scFv) ${ }^{3}$ (Fig. 1e-g). Abd-1 bound to GST-HRASG12V GTP $\gamma \mathrm{S}$ with a dose response (Fig. 1e). In contrast, no binding was observed when HRAS ${ }^{\mathrm{G} 12 \mathrm{~V}}$ was in complex with the anti-RAS scFv (Fig. 1f) or with the GDP-bound form of HRAS (Fig. 1g). The Kd for Abd-1 was estimated greater than $370 \mu \mathrm{M}$ against HRAS ${ }^{\mathrm{G} 12 \mathrm{~V}}$ GTP $\gamma$ S (Supplementary Fig. 1).

The chemical structure of Abd-1 is shown in Fig. 1 (MW:238.25, $\operatorname{clog} \mathrm{P} 2.33$, solubility $140 \mu \mathrm{M}$ ). We sought analogues with improved biophysical properties and potentially better $\mathrm{Kd}$. One candidate analogue (Abd-2, Fig. 1h) was identified ( $\mathrm{Mw}$ 259.26; $\log \mathrm{P} 1.83)$ with a solubility of $446 \mu \mathrm{M}$. Abd-2 has a benzodioxane bicyclic core with furanyl amide as the right-hand side of the molecule. SPR analysis showed that compound Abd-2 binds to both $\mathrm{HRAS}^{\mathrm{G} 12 \mathrm{~V}}$-GppNHp and $\mathrm{KRAS}^{\mathrm{G} 12 \mathrm{~V}-\mathrm{GppNHp}}$ (Fig. $1 \mathrm{~h}$ shows KRAS binding). Abd-2 is a racemic mixture and the enantiomers (compounds Abd-2a and Abd-2b) were tested for binding to KRASG12V-GppNHp by SPR (Fig. 1i, j). Both enantiomers bind to KRASG12V with similar properties. A truncated analogue of Abd-2, designated as Abd-3, also binds to $\mathrm{KRAS}^{\mathrm{G} 12 \mathrm{~V}}$-GppNHp, but with lower affinity than Abd-2 (Fig. 1k), showing the intrinsic binding properties of the benzodioxane core.

We measured the dissociation constant of Abd-2 using waterLOGSY ${ }^{37,38}$ showing a Kd of $235 \mu \mathrm{M}$ (Supplementary Fig. 2). We also confirmed that Abd-2 reproduced preferential binding to the activated form of KRAS ${ }^{\mathrm{G} 12 \mathrm{~V}}$-GppNHp compared with the form KRAS-GDP (Supplementary Fig. 3a) and no longer binds to KRAS ${ }^{\mathrm{G} 12 \mathrm{~V}}$-GppNHp in the presence of anti-RAS scFv (Supplementary Fig. 3b).

Antibody-derived compounds bind to KRAS near the switch regions. Protein crystallography was used to determine the KRAS-binding site for Abd-2 and for the truncated analogue Abd-3. Two different mutant KRAS-GppNHp proteins, G12D and $\mathrm{Q} 61 \mathrm{H}$ were crystallised, and the crystals were soaked with compounds to yield high-resolution structures (Fig. 2, Supplementary Table 1). Compounds Abd-2 and Abd-3 bind in a pocket adjacent to the RAS switch regions I and II (Fig. 2a, b) that has been previously described as a site of other small-molecule binding ${ }^{24,25,39}$ Residues lining the binding pocket in KRAS ${ }^{\mathrm{Q} 61 \mathrm{H}}$ include K5, L6, V7, S39, D54, I55, L56, Y71 and T74 (Supplementary Fig. 4). Electron density for Abd-2 was identified only

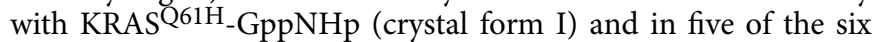
KRAS molecules in the asymmetric unit (the ligand density in chain B is used for illustration in Fig. 2a). The electron density is stronger around the benzodioxane core, with the furanyl amide substituent less well defined (Fig. 2a). No H-bond interactions 
a

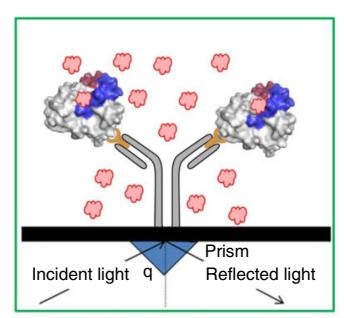

b

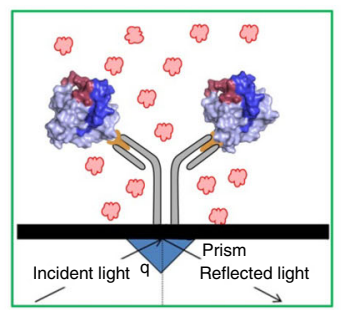

C

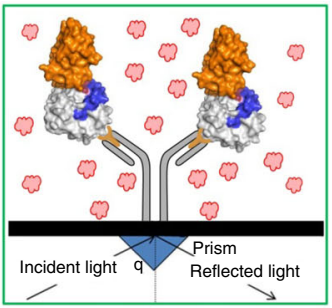

d
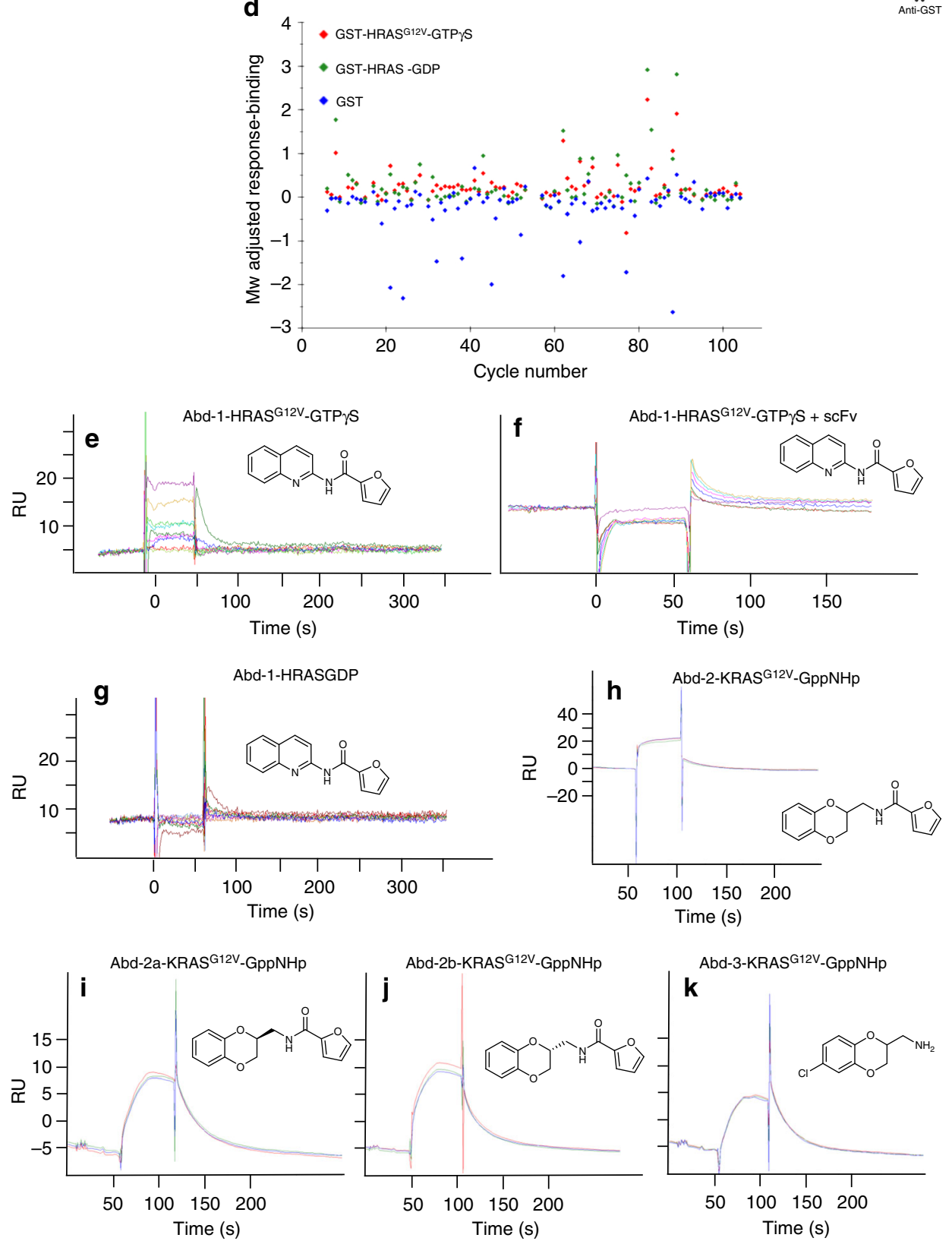

were observed between the compound and protein, with only van der Waals contacts with K5, L6, V7, E37, D38, S39, D54, I55, L56, G70, Y71 and T74. The electron density around furanyl amide provides an orientation marker for the binding pose of this compound and also the explanation of the competitive effect of anti-RAS antibody fragment on its binding (see below).

Analysis of the compound Abd-3-KRAS ${ }^{\mathrm{Q} 61 \mathrm{H}}$ complex (crystal form I) shows the best electron density in chain $\mathrm{B}$ (Fig. $2 \mathrm{~b}$ and Supplementary Fig. 4). The ligand terminal $\mathrm{NH}_{3}{ }^{+}$makes $\mathrm{H}$-bond interactions (salt bridge) to D54 carboxylate and to a well-defined water molecule (430) that is in turn also co-ordinated by an H-bond to D54 carboxylate and the hydroxyl group of S39. In contrast, Abd-3 has a rather different binding geometry in the KRASG12D crystal structure (crystal form II, Fig. 2c), as it is stabilized by two $\mathrm{H}$-bonds via the ligand terminal $\mathrm{NH}_{3}{ }^{+}$, one with E37 carboxylate and the other with the main chain carbonyl oxygen of D119 from a neighbouring protein in the KRAS ${ }^{\mathrm{G} 12 \mathrm{D}}$ crystal lattice. Thus, both interactions stabilize the terminal 
Fig. 1 Competition SPR identifies RAS-binding compounds. a, b The SPR screen involves a differential binding approach to identify compounds binding to activated, GTP-bound mutant RAS (HRASG12V), but not GDP-bound HRAS, indicated in (a) and (b), respectively. c Schematic representation of the cSPR approach. Anti-GST polyclonal goat antibody was captured on a CM5 SPR chip, and GST-RAS proteins were captured with anti-GST. Compounds that bind to a target protein (in this case HRAS) can be challenged with binding to the target protected by the high-affinity antibody fragment. If the binding regions coincide, the compound will not bind to the target. $\mathbf{d}$ A chemical fragment library of 656 compounds was initially screened as single points at $200 \mathrm{mM}$ using in the four channels (Fc) of a Biacore T100: Fc1: reference cell; Fc2: red diamond GST-HRASG12V_-GTP $\gamma$ S (active form of HRAS target); Fc3: green diamond GST-HRAS wild-type protein-GDP (inactive form of HRAS); Fc4: blue diamond recombinant GST only. e-g The RAS-binding compound Abd-1 was shown by SPR (dose-response sensogrammes using 3.9, 7.81, 15.6, 31.3, 62.5, 125, 250, 500, 1 and 2 mM compounds) to bind to mutant HRASG12V-GTP $\gamma$ S (e), but not to HRAS G12V_-GTPyS-anti-RAS scFv complex (f) or HRAS-GDP (g). h-k Analogues of the initial hit were identified and shown to bind to $\mathrm{KRAS}^{\mathrm{G} 12 \mathrm{~V}}$-GppNHp at $100 \mu \mathrm{M}$, run in triplicate

$-\mathrm{CH}_{2} \mathrm{NH}_{3}+$ functionality in a different orientation from the one observed for KRASQ61H, but it is directly influenced by the packing in crystal form II (Fig. 2b, c and Supplementary Table 1).

The mechanism by which the antibody fragment inhibits the binding of compounds was revealed by comparing the structures of HRAS ${ }^{\mathrm{G} 12 \mathrm{~V}_{-} \mathrm{Fv}^{3}}$ with KRAS ${ }^{\mathrm{G} 12 \mathrm{~V}_{-}}$-Abd-2 (Fig. 2d). Superimposing the complexes shows that the CDR2 region of the $\mathrm{VH}$ is oriented towards the binding pocket, where benzodioxane interacts with the side chain of K56 in CDR2, partly overlapping with the furanyl substituent (Fig. 2d). Structure analysis shows that intracellular antibody does not cause structural changes in HRAS $^{\mathrm{G} 12 \mathrm{~V}(3)}$ and the compound-binding pocket remains accessible (Supplementary Fig. 5). Therefore the competition occurs by displacement rather than allosteric changes in RAS protein.

A chemical series from the antibody-derived compound Abd-2. The initial hit antibody-derived compound gave us the anchor binding site on KRAS, from which to develop compounds to compete with RAS-effector PPIs. A chemical series was developed and representative structures are shown in Fig. 3a (Abd-4, 5, 6 and 7). High-resolution crystallography showed that all compounds bind in the same hydrophobic pocket near switch I (Fig. 3b, c and Supplementary Table 2) and with increasing potency (Supplementary Fig. 6). In the development of the series, efforts were focussed on the right-hand side (RHS) of the molecule (i.e. substituents of the dioxane), since crystallography consistently showed electron density predominantly around the benzodioxane core. Compound Abd-4 was extended from the amide group, but KRAS ${ }^{\mathrm{Q} 61 \mathrm{H}}$ crystal soaking only showed electron density in two of the six chains (the ligand density in chain $\mathrm{B}$ is illustrated in Fig. 3, and only around the benzodioxane core (Fig. 3b, c). No H-bond interactions were observed between the benzodioxane rings and protein, with only van der Waals contacts with K5, L6, V7, E37, D54, I55, L56, G70, Y71 and T74. Therefore, efforts were directed to substitutions on the left-hand side (LHS), on the benzene ring of the benzodioxane main core, targeting interactions with K5, D54 or S39.

Aromatic substituents at position 8 in Abd- 5 increased the level of electron density observed around the compound, and it was identified in all six chains of the asymmetric unit (chain $\mathrm{F}$ is illustrated in Fig. 3). Crystal soaking of KRASQ61H with Abd-5 showed the new pyridine ring leading to the side of the switch I region of KRAS (Fig. 3c). This compound forces D54 to rotate to allow the third ring to be accommodated in a pocket formed by S39, Y40, D54, I55 and L56. No H-bond interactions were identified between Abd-5 and the protein, and the only interactions identified were van der Waals contacts to K5, L6, V7, S39, Y40, R41, D54, I55, L56, G70, Y71 and T74. No interactions were observed from the RHS of the molecule.

Analysis of crystals soaked with Abd-5 indicated that exploration around the pyridine ring in positions 3 to 5 could gain extra interactions in the KRAS switch I region. Abd- 6 included a third ring (benzene) at position 3 of the pyridine ring in Abd-5 and a tetrahydropyran-4-carboxamide substituent in place of the benzamide derivative on the right-hand side (Fig. 3b, c). Soaked crystals showed electron density for the new aniline-based functionality, but no H-bond with the protein in any of the four chains where the compound was identified. The only interactions observed were van der Waals contacts to K5, L6, V7, S39, Y40, R41, D54, I55, L56, G70, Y71, T74 and G75, and also with amino acid residues from a neighbouring protein within the unit cell. The binding affinities of Abd-5 and Abd-6, measured using NMRbinding detection method Carr-Purcell-Meiboom-Gill (CPMG), a relaxation dispersion technique (RD) using proton NMR's of the ligand molecule as sensors for binding and unbinding kinetics and without any isotope labelling. In CPMG, signal reduction occurs with increased protein concentration ${ }^{40,41}$. This showed that Abd-5 and Abd-6 had improved affinities of $220 \mathrm{nM}$ and $38 \mathrm{nM}$ (respectively, Supplementary Fig. 6b and d)

An important feature in Abd-5 and Abd- 6 was the lack of interactions between KRAS ${ }^{\mathrm{Q} 61 \mathrm{H}}$ and the benzamide derivative (Abd-5) or the tetrahydropyran-4-carboxamide (Abd-6), substituted from the original furan group in Abd-2. The RHS of Abd6 was removed to reduce the molecular weight, but to maintain or increase the interaction with the protein. The new analogue, Abd7, gave improved crystallography results with full electron density for the compound (Fig. 3a-c) and with van der Waals contacts to K5, L6, V7, S39, Y40, R41, D54, I55, L56, G70, Y71, T74 and G75. Abd-7 was found in five out of six protein chains. Interactions to residues from a neighbouring protein within the unit cell were also identified, same as Abd-6.

The protein-binding capabilities of the most potent of this series of compounds (Abd-5, Abd-6 and Abd-7) was confirmed in an orthogonal assay (waterLOGSY) using KRAS ${ }^{G 12 V_{-G p p N H p}}$ (Supplementary Fig. 6). The spectra for each compound show that all the proton peaks have reverse polarity in the presence of the KRAS protein (Supplementary Fig. 6a, $c$ and e). The values of 220, 38 and $51 \mathrm{nM}$ were found, respectively, for compounds Abd5, Abd-6 and Abd-7 (Supplementary Fig. 6b, d, f). The ligand efficiencies values (each approximated to 0.3 ), molecular weights and solubilities for these three compounds are shown in Supplementary Fig. 6g.

KRAS-binding compounds inhibit RAS PPIs in cell assays. We have investigated the ability of the chemical series to inhibit RASeffector PPI using cell-based assays involving a RAS-effector BRET2 assay, the effect on downstream biomarker phosphorylation and tumour cell viability. A RAS PPI BRET2 toolbox has been developed to evaluate the in vivo effect of compounds on RAS-effector PPI of compounds ${ }^{42}$. This assay comprises transfection of HEK293T cells with plasmids to express BRET donor (fusions of either $\mathrm{K}, \mathrm{N}$ or HRAS, including a carboxy-terminal farnesylation signal tetrapeptide, with Renilla luciferase variant 8 , Rluc8) and acceptor molecules (fusions of effector proteins with $\mathrm{GFP}^{2}$ ), and permits the assessment of inhibitors of RAS-effector 
a
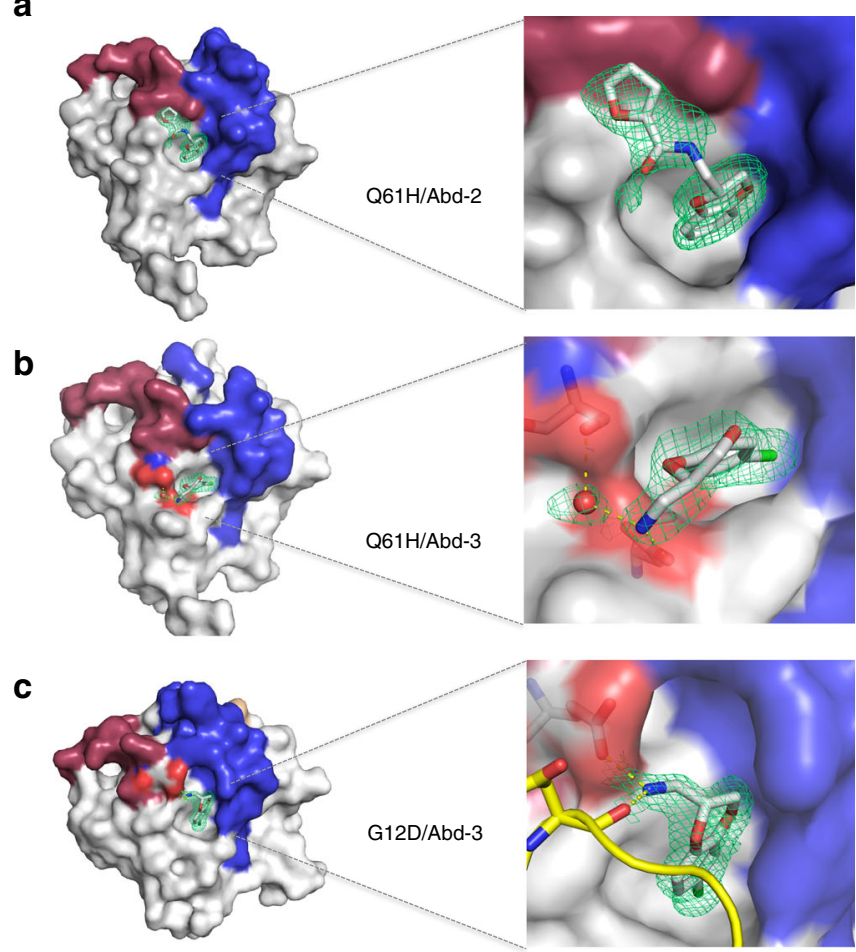

d

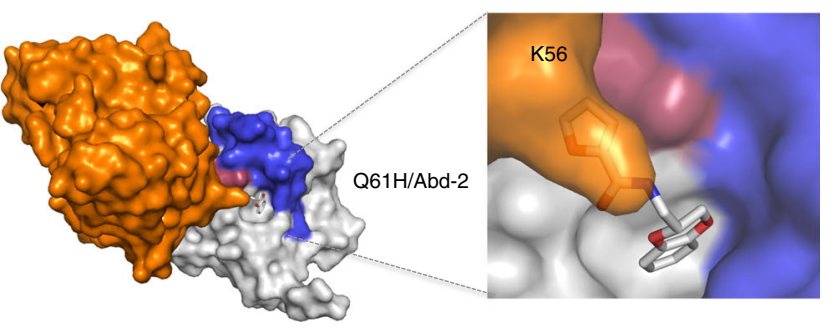

Fig. 2 Crystal analysis shows how compounds bind and VH competition results. KRASQ61H or KRASG12D protein crystals were soaked with compounds, and X-ray diffraction data were collected for determining the binding modes of the compounds. a KRAS ${ }^{\mathrm{Q} 61 \mathrm{H}}-\mathrm{GppNHp}$ soaked with Abd-2. The expanded view of the binding region of this compound (right hand panel) shows clear electron density (2mFo-DFc maps contoured at 1.0 r.m.s. green) attributed to the benzodioxane and furanyl amide parts of the compound. b, c Crystal structures and electron densities for Abd-3 soaked into KRAS $61 \mathrm{H}_{-}$GppNHp or KRAS ${ }^{\mathrm{G} 12 \mathrm{D}}$-GppNHp, respectively. The chlorine atom in Abd-3 is depicted in green. The Abd-3-KRAS

interactions differ in two mutants, but the $\mathrm{H}$-bond to a neighbouring molecule in the crystal lattice for G12D means that the Q61H complex is unencumbered by the crystal contacts (b). The switch I/II regions are coloured in red and blue, respectively, are defined here as 30-38 (switch I) and 60-76 (switch II). d Explanation for the competition of compound Abd-2 binding to RAS by steric hindrance. The left-hand panel shows a surface representation of mutant HRAS ${ }^{\mathrm{G} 12 \mathrm{~V}}$-GppNHp (light blue) and the anti-RAS VH from the Fv depicted in orange. The left-hand panel is the

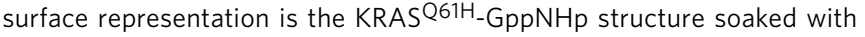
Abd-2, with anti-RAS VH superimposed on KRAS $61 \mathrm{H}_{-}$GppNHp. The expanded right-hand representation shows the predicted steric hindrance between $\mathrm{VH}$ and the compound, in particular VH CDR2 residue $\mathrm{K} 56$ (transparent, orange representation). Although the $\mathrm{K} 56$ side chain is flexible, it is prevented from rotating away from the clash with Abd-2 by steric hindrance with neighbouring regions of KRAS interaction. We determined the effect of Abd-7 on the interaction of KRAS ${ }^{\mathrm{G} 12 \mathrm{D}}$ and with PI3Ka and PI3K $\gamma$, CRAF RAS-binding domain (RBD) and RALGDS RAS-associating domain (RA) compared with the low-affinity Abd-2 Fig. 4a). Abd-2 has no effect on the BRET signal over a range of 5-20 $\mu \mathrm{M}$, while Abd-7 reduces the BRET signal at 5,10 and $20 \mu \mathrm{M}$ for all of the RASeffector PPIs tested. A similar inhibitory effect of Abd-7, but not Abd-2, was observed using five different glycine 12 mutations of KRAS interacting with the full-length CRAF-GFP ${ }^{2}$ fusion (Fig. 4b). Finally, we tested the efficacy of Abd-7, compared to Abd-2, in the BRET assays using other RAS family members, either NRAS ${ }^{\mathrm{Q} 61 \mathrm{H}}$ or HRAS ${ }^{\mathrm{G} 12 \mathrm{~V}}$, interacting with PI3Ka and PI3K $\gamma$, CRAF-RBD or full-length CRAF and RALGDS-RBD (respectively, Fig. 4c, d). Abd-7 interferes with all mutant RAS family member PPIs in this transfection assay. However, in this type of assay, protein expression levels are difficult to control due to the transient transfections, and the percentage of signal reduction may vary between repetitions or between different RAS-effector partners. The generation of stable cell lines could reduce the differences on protein expression.

In order to assess the effect of our compounds on endogenous RAS signalling, we analysed phosphorylation of AKT (downstream of RAS-PI3K signalling) and phosphorylation of ERK (downstream of RAS-RAF signalling) using DLD-1 cells (a colorectal line with KRASG13D mutation) and $\mathrm{H} 358$ cells (a NSCLC with KRAS ${ }^{\mathrm{G} 12 \mathrm{C}}$ mutation). The cells were starved for 24 $\mathrm{h}$, followed by incubation for $3 \mathrm{~h}$ with an increasing dose of Abd7 (range 2-20 $\mu \mathrm{M}$ ) and stimulated EGF for $10 \mathrm{~min}$ to activate KRAS signalling. Protein levels were determined by Western analysis (Fig. 5a, b). While no change of endogenous AKT or ERK $1 / 2$ was observed, inhibition of AKT phosphorylation (assessed with anti-pAKT Ser473 antibody) was observed in both cell lines, with response initiating between 2 and $5 \mu \mathrm{M}$, more than $50 \%$ at $10 \mu \mathrm{M}$ and complete inhibition at $20 \mu \mathrm{M}$. No change was observed in cyclophilin B (as a loading control on the Western blots) (Fig. 5a, b). Similar dose responses were obtained for inhibition of ERK1/2 phosphorylation by Abd-7 (assessed with anti-pERK1/2 antibody) treatment of the cells. EGF stimulates pERK production without affecting ERK1/2 levels, and diminution of pERK levels was found with a similar dose range of Abd-7 (Fig. 5a, b). We confirmed that Abd-7 is not directly binding to kinase proteins themselves, using a binding assay with a panel of kinase proteins, including RAF, MEK and PI3K (Supplementary Table 3), endorsing the conclusion that control of phosphorylation depends on the direct binding of Abd-7 to RAS protein rather than to other protein kinases. These cell assays show that the lead compound Abd-7 is cell permeable and it exerts its inhibitory function by interfering with PPI of RAS and effectors. Independent evidence for cellular uptake was obtained using a Caco-2 cell permeability assay (Papp A-B/B-A) 7.03/8.46 $\left(10^{-6} \mathrm{cms}^{-1}\right)$.

We carried out cell viability studies using a monolayer culture system with two human cancer cell lines with different RAS family member mutations (DLD-1 KRAS ${ }^{\mathrm{G} 13 \mathrm{D}}$ and HT1080 NRAS $\left.{ }^{\mathrm{Q} 1 \mathrm{~K}}\right)$. A dose response was carried out with Abd-2, Abd4, 5, 6 and 7. Figure 5c (DLD-1) and 5d (HT1080) show cell viability in the presence of $0-20 \mu \mathrm{M}$ compound after $72 \mathrm{~h}$ (Supplementary Fig. 7 shows viability at 24 and $48 \mathrm{~h}$ ). The lowest-affinity compounds, Abd-2 and Abd-4, show no effect on cell viability even at the highest doses (these compounds also do not show activity in the RAS biosensor BRET assay). Compounds Abd-5 and Abd- 6 have an effect on the viability (with Abd-5 showing a greater effect on DLD-1 viability); but even at $20 \mu \mathrm{M}$ 
a

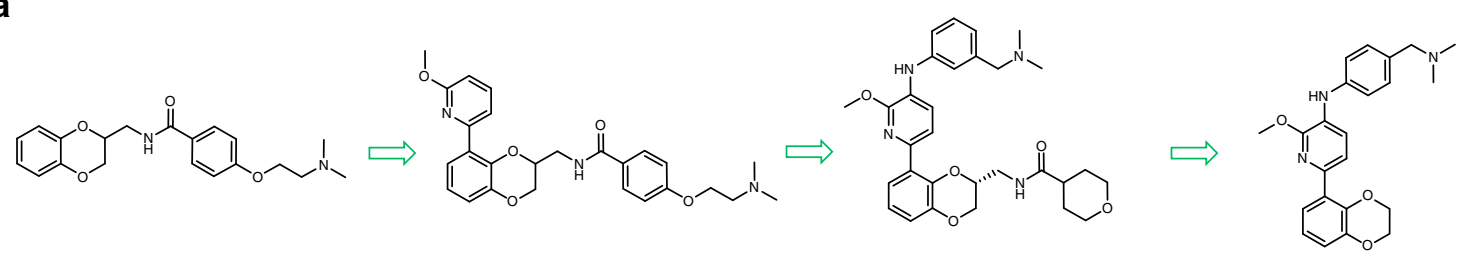

b

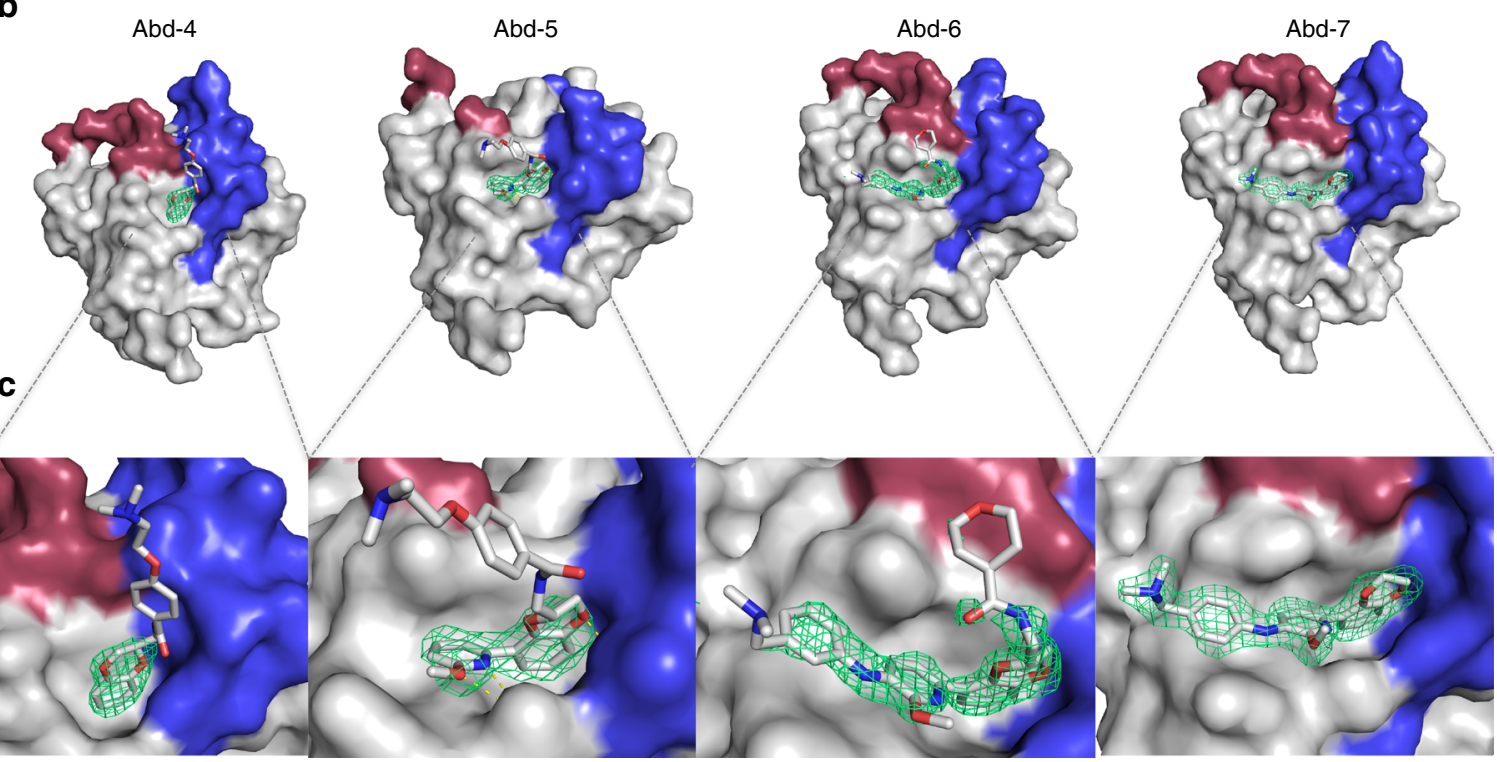

Fig. 3 RAS-binding series development from antibody-derived initial hit. Representative examples of KRAS-binding compounds Abd-4 to Abd-7 guided by structural biology information. a Chemical structures of the chemical series with numbering on different rings. $\mathbf{b}$ Crystal structures with the mode of binding of each compound to KRASQ61H_GppNHp (shown in grey) in the pocket close to the switch regions I (red) and II (blue). Each new analogue has extended its interaction with the protein, reaching to parts of the switch I region. c Expanded view to the compounds binding to KRAS, with the electron density identified in the crystallographic experiments depicted as a green mesh ( $2 \mathrm{mFo}-\mathrm{DFc}$ maps contoured at 1.0 r.m.s)

and after $72 \mathrm{~h}$, there are surviving cells following incubation with either compound. The most potent compound is Abd-7 (whose in vitro $\mathrm{Kd}$ is $51 \mathrm{nM}$ ) with an $\mathrm{IC}_{50}$ of $8 \mu \mathrm{M}$ in DLD-1 and $10 \mu \mathrm{M}$ in $\mathrm{HT} 1080$ at $72 \mathrm{~h}$ (similar values for the $\mathrm{IC}_{50}$ were found after $48 \mathrm{~h}$ (Supplementary Fig. 7f). These results showed that the ability of our chemical series to affect cancer cell viability relates to their binding properties, and that Abd-7 is the most cell-potent inhibitor affecting the viability of cancer cell lines in a single digit to low micromolar range.

\section{Discussion}

Intracellular antibodies are highly specific research tools for target validation ${ }^{3}$ nonetheless $\mathrm{scFv}$, single domain intracellular antibodies (iDAbs) ${ }^{13}$ and single camelid VH domains (nanobodies) ${ }^{43,44}$ have not been implemented as therapeutic agents. An alternative use of intracellular antibodies is to select small molecules that bind to the same region of target antigens and can thence potentially be developed into drugs $5,45,46$. Our work describes the use of an intracellular antibody fragment that competes RAS-effector $\mathrm{PPI}^{3}$, to select a compound in vitro from a chemical fragment library that binds to RAS family proteins at the cognate site. The method depends on a high-affinity interaction between the intracellular antibody fragments and to allow sustained interaction during the cSPR. This cannot be achieved using natural partner proteins (e.g. RAS-effectors) as these have low binding affinity with high $K_{\text {off }}$. We thus show in this work that a single domain intracellular antibody fragment, which was derived against mutant HRAS and used for target validation of RAS-effector PPIs, could be used in a competition assay to select RAS-binding compounds from a fragment library. This created a chemical basis for development, by medicinal chemistry and SAR, of a compound series with improved properties, guided by highresolution X-ray crystallography. We generated a soluble lead compound with low nM Kd, that is both cell permeable, was able to block RAS PPIs in human cancer cells, and to affect the viability of the cells. Although, various RAS inhibitors have been described in literature, ${ }^{24-32,47,48}$, in this paper we describe an approach for the development of RAS-effector inhibitors by combining different elements i.e. (i) the hit identification via a method of intracellular antibody fragment competition; (ii) structure-based

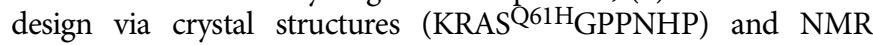
(waterLOGSY and CPMG); (iii) identification of clear structureactivity relationship (SAR) for the development of potent compounds against KRAS and (iv) the proof of concept in mechanistic and phenotypic cell assays.

Our medicinal chemistry, guided by high-resolution crystallography allowed the improvement of our initial Abd-2, that binds in a previously observed pocket, through to the nM-binding compound Abd-7 (Fig. 3). X-ray crystallography using crystal soaking showed how the initial hits bind to KRAS and how the antibody fragment $\mathrm{VH}$ interferes with this binding (Fig. 2d, Fig. 6) Our guided approach has led to the identification of a novel series of compounds that interfere with the oncogenic function of RAS and whose binding features are confirmed. Different groups have described compounds binding to this same pocket, however, there has been no structure-based design of direct RAS-effector inhibitors done in that region. The difficulties of identifying a suitable crystal packing conditions of mutant KRAS to soak compounds contributes to the difficulties of generating SAR and, consequentially, of generating highly potent 
a

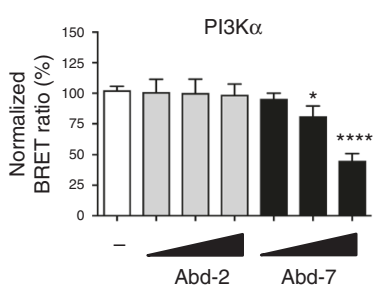

b
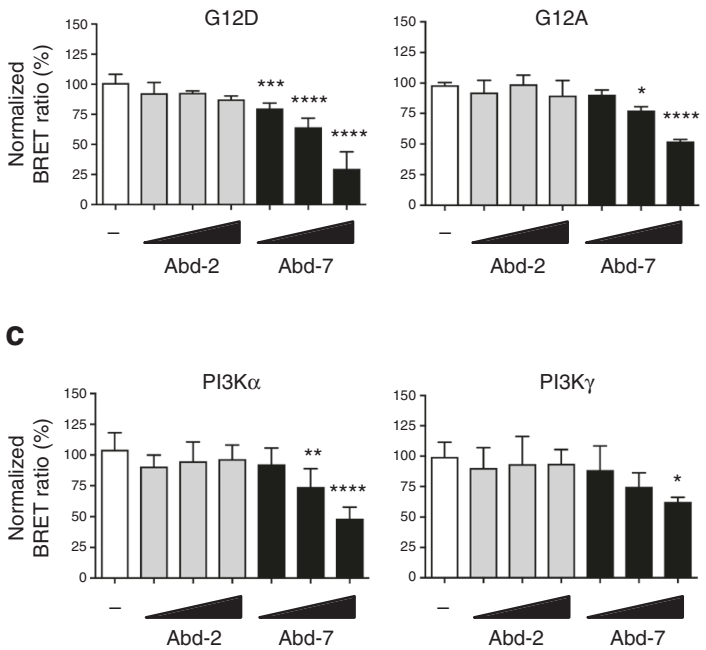

d

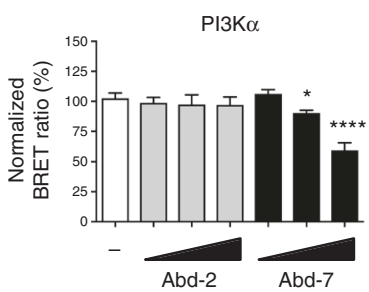

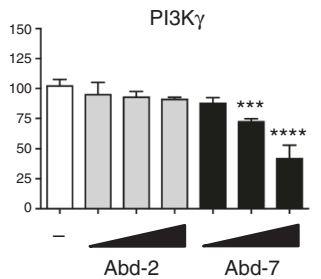

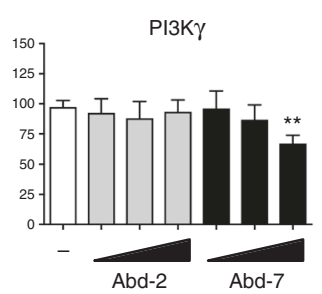

KRASG12D + RBD
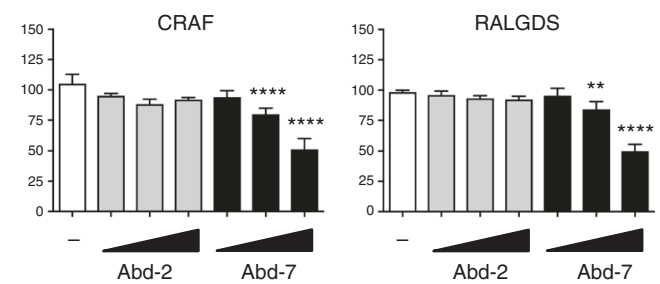

KRASG12X + CRAF FL
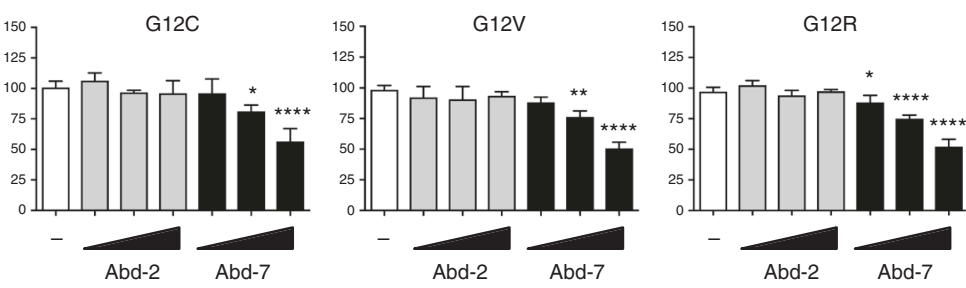

NRASQ61H
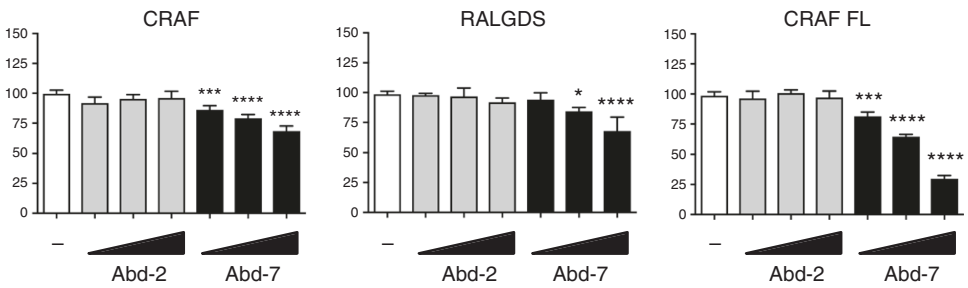

HRASG12V
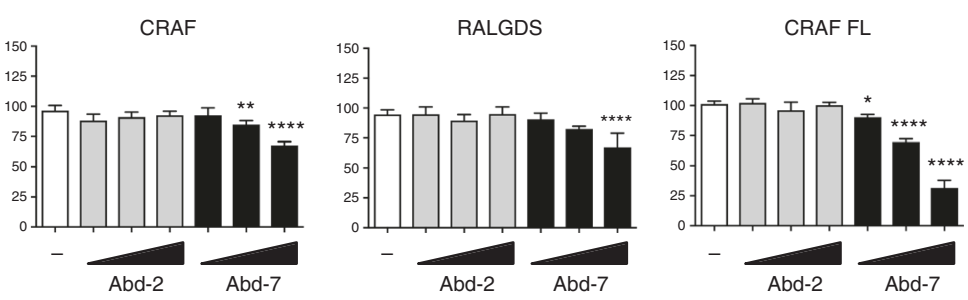

Fig. 4 Abd-7 disrupting RAS-effector interactions. HEK293T cells were transfected with different BRET-based RAS biosensor expression vectors to evaluate the inhibition of RAS PPI in cells by compound Abd-7. Transfection vector encoded full-length RAS was fused to the donor molecule RLuc8 and the effectors fused to the acceptor molecule GFP 2 . a Effect of Abd-2 and Abd-7 on KRASG12D interaction with PI3K $\alpha$, PI3K $\gamma$, CRAF or RALGDS. The BRET signal is plotted as a \% of control cells treated with DMSO only and dose response to 5, 10 and $20 \mu \mathrm{M}$ of each compound. $\mathbf{b}$ Effect of Abd-2 and Abd-7 on the BRET signal from interaction of KRAS ${ }^{G 12}$ mutants (Rluc8-KRAS G12) and full-length CRAF (GFP2-CRAF FL). c, $\mathbf{d}$ Effect of Abd-2 and Abd-7 on the interaction of NRASQ61H (c) and HRASG12V (d) with various RAS effectors domain and with full-length CRAF. The BRET ratio corresponds to the light emitted by the $\mathrm{GFP}^{2}$ acceptor constructs $(515 \mathrm{~nm} \pm 30$ ) upon addition of Coelenterazine 400 a divided by the light emitted by the RLuc8 donor constructs (410 nm \pm 80 ). The normalized BRET ratio is the BRET ratio normalized to the DMSO negative and calculated as follows: (BRET compound $\left./ \mathrm{BRET}_{\mathrm{DMSO}}\right) \times 100$, where $B_{\text {BRET }}$ compound corresponds to the BRET ratio for the compound-treated cells, BRET DMSo to the DMSO-treated cells. Each experiment was repeated at least three times. Statistical analyses were performed using a one-way ANOVA followed by Dunnett's post-tests $\left({ }^{\star} P<0.05,{ }^{\star \star} P<0.01,{ }^{\star \star \star} P<0.001,{ }^{\star \star \star \star} P<\right.$ 0.0001). Where error bars are presented, they correspond to mean values \pm SD of biological repeats (a-c)

compounds binding to pocket. We have solved this by exploiting and optimizing known crystallisation conditions for KRAS $\mathrm{Q}^{\mathrm{H}} \mathrm{H}$ (PDB code 3GFT).

The initial fragment compound (Abd-2) was improved by introducing pyridine functionalities to position 8 of the benzene ring from the benzodioxane moiety, enhancing the $\mathrm{Kd}$ from $\mu \mathrm{M}$ to $\mathrm{nM}$ with increased ligand efficiency values from 0.26 of Abd-2 to 0.34 of Abd-7 (Supplementary Fig. 6). An expansion of the interactions is observed when Abd-4 was evolved to Abd-7 (Supplementary Fig. 8). One of our objectives was to show that intracellular antibody fragments could be used for chemical compound hit identification and to find compounds that emulate the inhibition of PPI shown by the antibody ${ }^{3}$ in cells. We used a
BRET2-based assay to evaluate the intracellular inhibition of RAS PPI by Abd-7, compared to the low affinity compound Abd- 2 and showed that Abd-7 impairs the PPI of various mutant KRAS proteins with PI3K, CRAF and RALGDS as well as NRASQ61H and HRAS ${ }^{\mathrm{G} 12 \mathrm{~V}}$ but Abd-2 does not (Fig. 4). RAS-dependent signalling occurs via several kinase molecules, including phosphorylation of AKT (the RAS-PI3K pathway) and ERK (the RASRAF pathway). The Abd-7 compound inhibits phosphorylation of both downstream biomarkers (Fig. 4a, b) in colorectal cancer (DLD-1, KRASG13D) and non-small cell lung cancer (H538, KRAS $^{\text {G12C) }}$ human cell lines in a dose dependent way, with reduction of AKT phosphorylation starting at $2 \mu \mathrm{M}$. These effects occur within $2 \mathrm{~h}$ of Abd-7 treatment while there is no effect on 
a

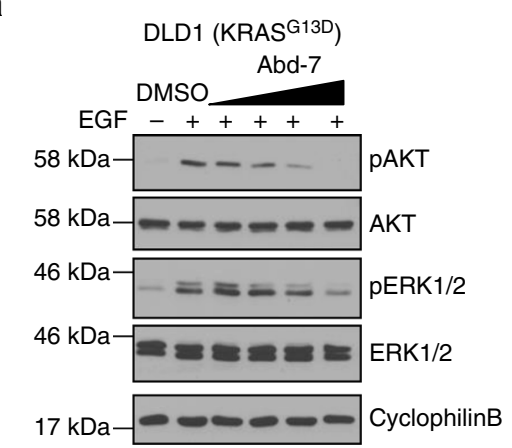

b

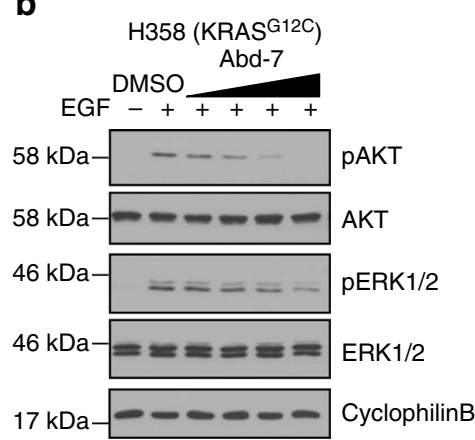

C

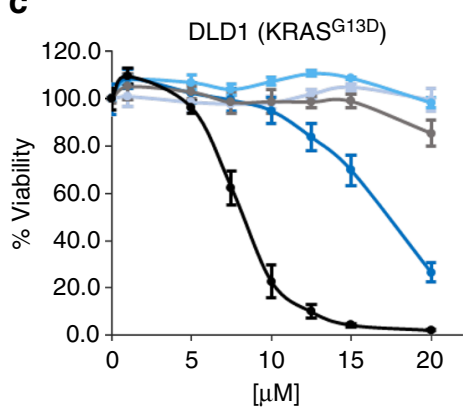

d

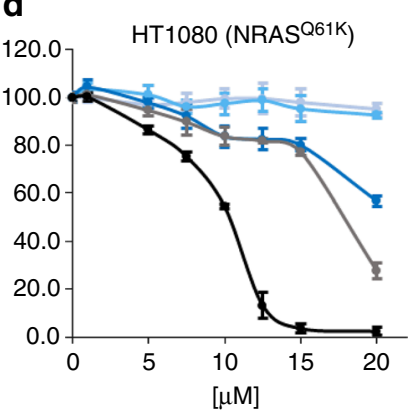

e

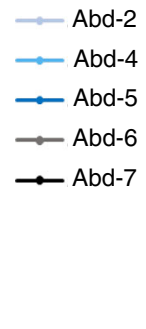

Fig. 5 Abd-7 results on RAS-dependent signalling pathways and cell viability. a, b DLD-1 (a) or H358 (b) cells were serum-starved for $24 \mathrm{~h}$, incubated in mono-layer with Abd-7 in a range from 2, 5, 10 and $20 \mu \mathrm{M}$ for $3 \mathrm{~h}$ and stimulated with EGF 10 min. Proteins were extracted and separated by SDS-PAGE and transferred to membranes for Western analysis with anti-pAKT, anti-pERK, anti-pan AKT and anti-pan ERK. Anti-cyclophilin B antibody was the loading control. Signal was developed using standard ECL. c-e Effects of compounds Abd-2, Abd-4, Abd-5, Abd-6, and Abd-7 on the viability of human cancer cells lines was assessed for a 2-D culture of DLD-1 (mutant KRASG13D) cells and HT1080 cells (mutant NRASQ61K). The cells were treated with a dose range from $0 \mu \mathrm{M}$ to $20 \mu$ and incubated for $72 \mathrm{~h}$ when cell viability was assessed using CellTitreGlo. In each case, the data are normalized to cells treated with DMSO only. $\mathbf{c}$ is DLD-1 and $\mathbf{d}$ is HT1080. e shows the colour coding for the different compounds. Each experiment was repeated at least three times $(\mathbf{a}, \mathbf{b})$ and four times $(\mathbf{c}, \mathbf{d})$. Where error bars are presented, they correspond to mean values \pm SD of biological repeats

the overall AKT or ERK protein levels. Abd-7 is, therefore, an inhibitor of RAS-effector PPI. The mechanism by which Abd-7 interferes with RAS-effector PPI is indicated from the crystal structure data. The binding of the CRAF, RALGDS and PI3K effectors to RAS is similar and very close to the binding site of Abd-7. In Fig. 6, RAS with bound Abd-7 is superimposed to structures of RAS-effector complexes showing that the terminal tertiary ammonium group, and adjacent phenyl ring, of Abd-7 overlaps with the bound effector structures. The competition effect of Abd-7 on the binding of the effectors with RAS in cells, can therefore be interpreted as steric hindrance of the lower affinity effectors by the higher affinity Abd-7. However, despite observing similar steric disruption of Abd-7 (Fig. 6), there are differences observed in the reduction of phosphorylation of pAKT and pERK in cells. These differences could be associated with the variations in affinity of the effectors towards KRAS. For example, Pi3K has an estimated affinity of $3.2 \mu \mathrm{M}$, while RAF has an affinity of $0.08 \mu \mathrm{M}^{6}$.

The susceptibility of cancer cells to the compounds in our chemical series was compared between the two human cell lines with different RAS family mutations (DLD-1 with mutant KRAS $^{\mathrm{G} 13 \mathrm{D}}$ and HT1080 with mutant NRASQ61K) using standard viability assays. The effect of the compounds on cell survival correlated with the potency of the compounds in binding using in vitro NMR and crystallography. The early compound (Abd-2), that was the direct descendent of the initial hit obtained using the cSPR, had not effect on either cell type, up to $72 \mathrm{~h}$ and the maximum concentration used $(20 \mu \mathrm{M})$ (Fig. 5c, d). Compound Abd-7 displayed the highest $\mathrm{IC}_{50}$ (approximately $8 \mu \mathrm{M}$ in DLD-1 and $10 \mu \mathrm{M}$ in HT1080 at $48 \mathrm{~h}$, (Supplementary Fig. 7), had the lowest $\mathrm{Kd}(51 \mathrm{nM})$ and shows consistent inhibitory effects in the cell-based BRET assay and the biomarker assay. The observed discrepancy between affinity (in vitro $\mathrm{Kd}$ ) and efficacy $\left(\mathrm{IC}_{50}\right.$ in cells) is a known challenge that can be addressed through chemistry. A comparison between Abd-6 and Abd-7 affinity Kds and cell $\mathrm{IC}_{50}$ demonstrates that by chemical modifications, one can increase cell potency while maintaining a similar-affinity $\mathrm{Kd}$. Further increase of potency could be achieved by new analogue synthesis based on structural biology information as demonstrated in our work. In addition, it is also known that discrepancies between in vitro and in cellulo potencies can be associated with targets, such as RAS, with high conformational variability and allosteric modulators ${ }^{49,50}$. Furthermore, the discrepancy could be exacerbated by permeability, efflux and free drug vs total drug availability, target location and biochemical state.

In summary, our results show that intracellular antibody-based selection of small compound ligands for specific proteins is practical and should provide a means to make compounds for disrupting abnormal protein function in any disease. Antibody fragments can be sequentially used for target validation and PPI epitope determination prior to drug development. Our approach allowed us to develop a series of compounds that bind to KRAS with high affinity, interfere with RAS PPI and inhibit RASdependent signalling in human tumour cells. This realizes the potential of allowing the replacement of antibody fragments (macrodrugs) with small molecule (conventional) potential drugs.

\section{Methods}

Fragment library. A fragment library comprising 656 compounds, triaged for potential drug-like precursors, was used with molecular weight range from 94 to $341 \mathrm{Da}$, composed of chemical fragments that followed the "rule of three" 
a

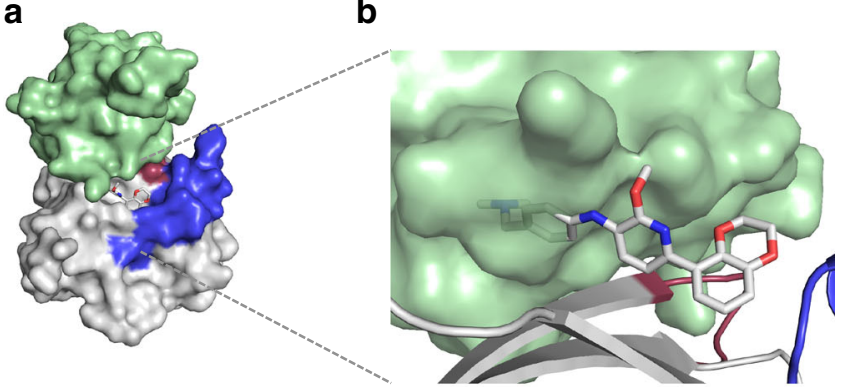

C

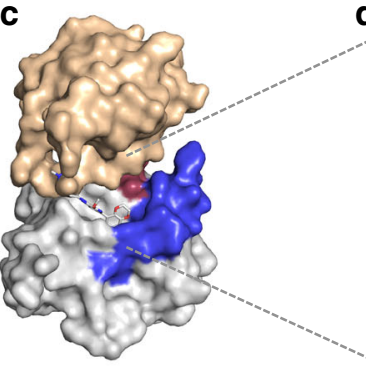

e

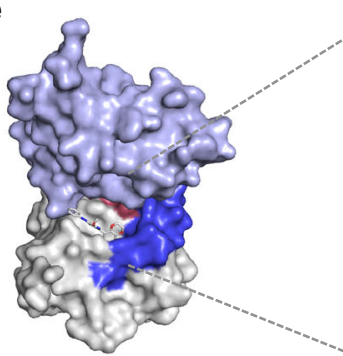

d
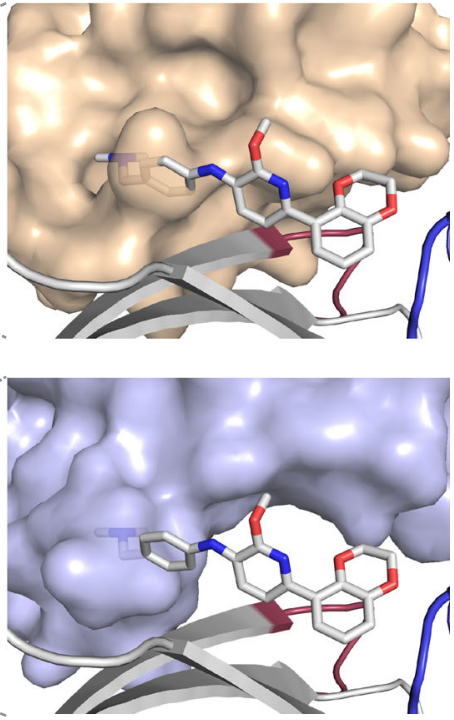

Fig. 6 Superimposed structures of $\mathrm{KRAS}_{169} \mathrm{Q61H}_{-} \mathrm{Abd}-7$ and RAS-effectors (RAF, Pi3K and RALGDS). The potential interactions that could prevent Abd-7 and a RAS effector binding simultaneously to the same KRAS molecule have been modelled by overlaying the structure of the $\mathrm{KRAS}_{169} \mathrm{Q61H}_{\text {-Abd-7 }}$ complex onto published structures. In each case, simultaneous binding of KRAS to Abd-7 and the effector is sterically forbidden. a, b Overlay with HRAS-CRAF RBD (PDB 4G3X). Abd-7 would overlap with residues 62-67 of CRAF. c, d Overlay with HRAS-RALGDS RBD (PDB 1LFD). Abd-7 would overlap with residues 29-31 of RALGDS. e, $\mathbf{f}$ Overlay with HRAS-PI3K $\gamma$ RBD (PDB 1HE8). Abd-7 would overlap with residues 227-229 for PI3K

(molecular weight $\leq 300 \mathrm{Da}, \operatorname{clogP} \leq 3$, the number of hydrogen bond donors and acceptors each $<3$ and the number of rotatable bonds $<3$ ) and small molecules above $300 \mathrm{Da}$. Each compound was dissolved at $200 \mathrm{mM}$ in 100\% DMSO and 41 compounds were removed from the library because of insolubility in DMSO i.e. from the library, 615 useful compounds could be screened at the concentrations used. The library was replica plated $\left(20 \mathrm{mM}\right.$ concentration) and stored at $-80^{\circ} \mathrm{C}$. The initial hit compound (Maybridge) was $\mathrm{N}$-(2-quinolinyl)-2-furamide $\left(\mathrm{C}_{14} \mathrm{H}_{10} \mathrm{~N}_{2} \mathrm{O}_{2}\right)$, product code HTS05481, MW:238.2456, clogP 2.33, Rotatable bonds: $2, \mathrm{H}$-bonds donor: $1, \mathrm{H}$-bonds acceptor 4 .

Recombinant protein expression for SPR and NMR. Recombinant GST fusion RAS proteins were prepared by expression of HRAS (1-166) HRAS ${ }^{\mathrm{G} 12 \mathrm{~V}}$ or KRAS $^{\mathrm{G} 12 \mathrm{~V}}$ cDNA cloned into the pGEX-2T vector in-frame with an N-terminal glutathione-s-transferase. pGEX-HRAS(wt) and pGEX-HRAS ${ }^{\mathrm{G} 12 \mathrm{~V}}$ plasmids were transformed into E. coli $\mathrm{C} 41(\mathrm{DE} 3)$. Bacterial cells were cultured at $37^{\circ} \mathrm{C}$ to an $\mathrm{OD}_{600}$ of 0.6 and induced with IPTG (isopropyl 1-thio-beta-D-galactopyranoside, final concentration $0.1 \mathrm{mM}$ ) at $30^{\circ} \mathrm{C}$ for $5 \mathrm{~h}$. The bacteria cultures were harvested by centrifugation and the cell pellets re-suspended in $140 \mathrm{mM} \mathrm{NaCl}, 2.7 \mathrm{mM} \mathrm{KCl}$, $10 \mathrm{mM} \mathrm{NaH}_{2} \mathrm{PO}_{4}, 1.8 \mathrm{mM} \mathrm{KH}_{2} \mathrm{PO}_{4}, 1 \mathrm{mM}$ EDTA, $2 \mathrm{mM} \mathrm{MgCl} 2 \mathrm{pH}$ 7.4. The proteins were extracted by cell disruption (Constant Systems Ltd., UK) at 25,000 psi at $4{ }^{\circ} \mathrm{C}$. The GST-fusion proteins were purified by glutathione-sepharose column chromatography (GE Healthcare) and eluted with $50 \mathrm{mM}$ Tris- $\mathrm{HCl} \mathrm{pH} 8.0$, $10 \mathrm{mM}$ reduced glutathione, $1 \mathrm{mM} \mathrm{DTT}, 2 \mathrm{mM} \mathrm{MgCl}$. The eluted proteins were dialysed against $50 \mathrm{mM}$ Tris- $\mathrm{HCl} \mathrm{pH} \mathrm{8.0,1} \mathrm{mM} \mathrm{DTT,} 2 \mathrm{mM} \mathrm{MgCl}_{2}$ and concentrated to $10 \mathrm{mg} / \mathrm{ml}$ using a Biomax-30 ULTRAFREE-15 centrifugal filter device

(Millipore). To exchange endogenous guanidine nucleotide bound to RAS to GDP or GTP analogue, purified GST-RAS proteins were loaded with GTP $\gamma$ S, GppNHp or GDP (Sigma). Nucleotide exchange for SPR and NMR samples was done by preparing a final solution of $1 \mathrm{ml}$ containing $400 \mathrm{ul}$ of KRAS protein (final 0.63 $\mathrm{mM}), 94 \mu \mathrm{l}$ of GPPNHP (16 times excess), $100 \mu \mathrm{l}$ of alkaline phosphatase buffer [0.5 mM Tris Ph 8.5, $10 \mathrm{mM}$ EDTA, $2 \mathrm{M}\left(\mathrm{NH}_{4}\right)_{2} \mathrm{SO}_{4}$ ], $100 \mu \mathrm{l}$ of alkaline phosphatase $\left(30\right.$ units $/ \mathrm{ml}$ ) and $307 \mu \mathrm{l}$ of $\mathrm{H}_{2} \mathrm{O}^{51}$. KRAS protein samples were concentrated using Vivapore $10 / 20 \mathrm{ml}$ concentrator $(7.5 \mathrm{kDa}$ molecular weight cut-off; Sartorius Vivapore). The proteins were further purified by gel filtration on a HiLoad Superdex 75 10/300 GL column (GE Healthcare, Uppsala, Sweden) in a buffer containing $10 \mathrm{mM}$ PBS pH 7.4, $5 \mathrm{mM} \mathrm{MgCl} 2$ at a flow rate of $0.5 \mathrm{ml} / \mathrm{min}$. Fractions corresponding to the protein were pooled and concentrated. Protein concentration was determined by extinction coefficient at $280 \mathrm{~nm}$ by using ProtParam tool. Protein purity was analysed by SDS-PAGE stained with Instant Blue (Expedeon). For purification of anti-RAS scFv or VH, the plasmids pRK-HISTEVscFv or pRK-HISTEV-VH were prepared by sub-cloning scFv or VH fragment into the pRK-HISTEV vector giving in-frame fusion with a $6 \mathrm{x}$ histidine tag and a TEV protease site. The plasmids were transformed into C41 (DE3), cultured at $37^{\circ} \mathrm{C}$ to an $\mathrm{OD}_{600}$ of 0.6 and induced with IPTG (final $0.5 \mathrm{mM}$ ) at $16^{\circ} \mathrm{C}$ for 12 hours. $\mathrm{scFv}$ protein was extracted from bacteria pellets using sonication and a French press with the extraction buffer ( $25 \mathrm{mM}$ Na phosphate, pH 7.4, $500 \mathrm{mM} \mathrm{NaCl}, 20 \mathrm{mM}$ imidazole) and purified using His-Trap Ni-affinity columns (GE Healthcare) employing gradient elution (20-300 $\mathrm{mM}$ imidazole). The his-tag peptide was removed from the purified protein by treatment with TEV protease and dialysed in $20 \mathrm{mM}$ Tris- $\mathrm{HCl}$ pH8.0, $300 \mathrm{mM} \mathrm{NaCl}, 20 \mathrm{mM}$ imidazole at $4{ }^{\circ} \mathrm{C}$ overnight. The scFv was purified again by passing through a Ni-NTA agarose column (Qiagen) and by gel filtration on a HiLoad Superdex-75 HR column (GE Healthcare) in $20 \mathrm{mM}$ Tris- $\mathrm{HCl} \mathrm{pH8.0,250} \mathrm{mM} \mathrm{NaCl}$ and concentrated to $10 \mathrm{mg} /$ $\mathrm{ml}$ for storage.

\section{Recombinant protein expression for crystallography. $\mathrm{KRAS}_{169}{ }^{\mathrm{Q} 61 \mathrm{H}}$ and} KRAS $_{188}{ }_{\text {G12D }}$ cDNAs were cloned into the pRK-172 vector using NdeI and BamHI restriction sites, in-frame with an N-terminal 6x his-tag and the TEV protease recognition site. Plasmids containing pRK-172-KRAS ${ }_{169} \mathrm{Q}^{2} 1 \mathrm{H}$ and $\mathrm{KRAS}_{188} \mathrm{G} 12 \mathrm{D}$ sequences were transformed individually into B834(DE3)pLysS cells, which were grown in $25 \mathrm{ml} \mathrm{LB}$ medium with $50 \mu \mathrm{g} / \mathrm{ml}$ carbenicillin and $34 \mu \mathrm{g} / \mathrm{ml}$ chloramphenicol for 16 hours at $37^{\circ} \mathrm{C}$, before adding to $11 \mathrm{LB}$ medium containing the same antibiotics. Protein expression was induced when cells reached an $\mathrm{OD}_{600}$ of 0.6 by addition of IPTG to a final concentration of $0.5 \mathrm{mM}$, followed by overnight incubation at $16^{\circ} \mathrm{C}$. Bacteria were harvested by centrifugation $(5180 \mathrm{~g}, 30$ min, $4^{\circ} \mathrm{C}$ ), resuspended in $60 \mathrm{ml}$ of lysis buffer $50 \mathrm{mM}$ Tris- $\mathrm{HCl}, \mathrm{pH} 7.5,500 \mathrm{mM}$ $\mathrm{NaCl}, 5 \mathrm{mM} \mathrm{MgCl}$ and $10 \mathrm{mM}$ imidazole also containing one EDTA-free protease inhibitor cocktail table (Roche Diagnostics, Mannheim, Germany). Cells were lysed by sonication using five $30 \mathrm{~s}$ pulses at level of 16 and insoluble debris removed by centrifugation $\left(75,600 \mathrm{~g}, 20 \mathrm{~min}\right.$, and $\left.4^{\circ} \mathrm{C}\right)$. The supernatant was applied to a column of nickel agarose beads (Invitrogen) by gravity, the beads were washed twice with lysis buffer containing $50 \mathrm{mM}$ imidazole and bound proteins were eluted in $50 \mathrm{mM}$ Tris- $\mathrm{HCl}, \mathrm{pH} 7.5,500 \mathrm{mM} \mathrm{NaCl}, 5 \mathrm{mM} \mathrm{MgCl}_{2}, 300 \mathrm{mM}$ imidazole.

HIS-tagged TEV protease $(1.4 \mathrm{mg} / \mathrm{ml})$ was added to the $\mathrm{KRAS}_{188}{ }^{\mathrm{G} 12 \mathrm{D}}$ at a ratio of 1:100 to the eluate and the sample dialysed against $50 \mathrm{mM}$ Tris- $\mathrm{HCl}, \mathrm{pH} 7.5$, $500 \mathrm{mM} \mathrm{NaCl}, 5 \mathrm{mM} \mathrm{MgCl}_{2}$, overnight at $4{ }^{\circ} \mathrm{C}$. The TEV protease and cleaved HIS-tag fragment were removed by re-application of the digestion to nickel agarose beads (Invitrogen). Samples containing KRAS protein were concentrated using Vivapore $10 / 20 \mathrm{ml}$ concentrator $(7.5 \mathrm{kDa}$ molecular weight cut-off; Sartorius Vivapore). Endogenous guanidine nucleotide bound to RAS was exchanged to a GTP analogue and purified KRAS proteins were loaded with GppNHp (Sigma) following the same protocol described for the SPR and NMR experiments. The proteins were further purified by gel filtration using a Superdex 75 Increase 10/300 GL column (GE Healthcare, Uppsala, Sweden). $\mathrm{KRAS}_{169} \mathrm{Q}^{\mathrm{C} 1 \mathrm{H}}$ was equilibrated with $20 \mathrm{mM}$ HEPES pH 8.0, $150 \mathrm{mM} \mathrm{NaCl}, 5 \mathrm{mM} \mathrm{MgCl}$ and $1 \mathrm{mM} \mathrm{DTT}$ and applied to the column at a flow rate of $0.5 \mathrm{ml} / \mathrm{min}$. For $\mathrm{KRAS}_{188} \mathrm{G12D}^{\mathrm{D}}$ buffer used to equilibrate the column and elute the protein was $25 \mathrm{mM}$ TrisCl, $\mathrm{pH} 8.0,100 \mathrm{mM}$ $\mathrm{NaCl}, 5 \mathrm{mM} \mathrm{MgCl}$ and $1 \mathrm{mM}$ TCEP. Fractions corresponding to KRAS were pooled and concentrated to $45-75 \mathrm{mg} / \mathrm{ml}$ for crystallisation trials. Protein concentration was determined from the extinction coefficient at $280 \mathrm{~nm}$ using ProtParam tool. Protein purity was confirmed by SDS-PAGE stained with Instant Blue (Expedeon).

HRAS small-molecule screening and competitive SPR. A BIAcore T100 (GE Healthcare) was used to screen the fragment library for RAS binders. A polyclonal goat anti-GST antibody (GE Healthcare) was immobilized on a CM5 sensor chip (GE Healthcare) by the amine coupling method. To immobilize the antibody on CM5 chip, the chip was first activated by injecting $100 \mu \mathrm{l}$ mixture of $0.2 \mathrm{M}$ EDC ( $\mathrm{N}$-ethyl- $\mathrm{N}$-(dimethylaminopropyl) carbodiimide hydrochloride) and $0.05 \mathrm{M}$ NHS ( $N$-hydroxysuccinimide) at $10 \mu \mathrm{l} / \mathrm{min}$ flow rate. Furthermore, $100 \mu \mathrm{g} / \mathrm{ml}$ anti-GST antibody in $10 \mathrm{mM}$ sodium acetate, pH 5.0 was injected at $5 \mu \mathrm{l} / \mathrm{min}$ for $900 \mathrm{~s}$ and immobilized until 20,000 25,000 RU. After immobilization the chip was immediately inactivated by injecting $1 \mathrm{M}$ ethanolamine, $\mathrm{pH} 8.5$ at $10 \mu \mathrm{l} / \mathrm{min}$ for $600 \mathrm{~s}$. The chip was kept running in the HBS buffer (GE Healthcare) comprising $10 \mathrm{mM}$ HEPES, pH 8.0, $150 \mathrm{mM}$ NaCl. Of all, $5 \mu \mathrm{g} / \mathrm{ml}$ recombinant GST, GST- 


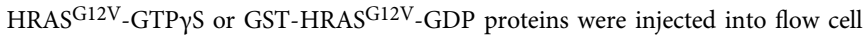
$\mathrm{Fc} 4, \mathrm{Fc} 2$ and $\mathrm{Fc} 3$, respectively for trapping through the immobilized anti-GST antibody. The GST-HRAS G12V_GTP $\gamma$ S, GST-KRAS ${ }^{\mathrm{G} 12 \mathrm{~V}}$-GppNHpp, or GSTHRAS $^{\mathrm{G} 12 \mathrm{~V}}$-GDP proteins were injected at $5 \mu \mathrm{l} / \mathrm{min}$ for $900 \mathrm{~s}$ and usually reached approximately $2000-2500 \mathrm{RU}$. The GST was injected at same flow rate until about $1200-1350 \mathrm{RU}$ which is 0.54 times less than the GST-HRAS ${ }^{\mathrm{G} 12 \mathrm{~V}}$-GTP $\gamma \mathrm{S}$ or GSTHRAS-GDP capture amounts, taking into consideration relative molecular weights (GST, $26 \mathrm{KDa}$, GST-RAS, $48 \mathrm{KDa}$, respectively). Before fragment library screening, the running buffer was replaced by $20 \mathrm{mM}$ Tris, $\mathrm{pH} 8,150 \mathrm{mM} \mathrm{NaCl}, 5 \mathrm{mM}$ $\mathrm{MgCl}_{2}, 5 \%$ DMSO. DMSO solvent correction curves were generated by injecting the running buffers with serial concentrations of DMSO ranging from 4.5 to $6 \%$. For fragment screening, each compound was diluted at $200 \mu \mathrm{M}$ or $1 \mathrm{mM}, 5 \%$ DMSO in $20 \mathrm{mM}$ Tris, $\mathrm{pH} 8,150 \mathrm{mM} \mathrm{NaCl}, 5 \mathrm{mM} \mathrm{MgCl} 2$ buffer in a polypropylene 96 well plate. The individual compounds were injected at $30 \mu \mathrm{l}$ for $60 \mathrm{~s}$ at $30 \mathrm{\mu l} / \mathrm{min}$ flow rate over flow cells Fc1, Fc2, Fc3 and Fc4. The captured GST and GST-RAS were removed from the chip by rinsing with $40 \mu \mathrm{l} 10 \mathrm{mM}$ glycine- $\mathrm{HCl}$, $\mathrm{pH} 2.1$ at $20 \mu \mathrm{l} / \mathrm{min}$ flow rate after every 48 compounds sequential injection. The chip was regenerated by injecting new GST and GST-RAS proteins as described above.

For competitive SPR (cSPR) assays between anti-RAS scFv and candidate fragment binder, after immobilizing anti-GST polyclonal antibody was immobilized on CM5 sensor chip as described above, then $5 \mu \mathrm{g} / \mathrm{ml}$ GST-HRASGTP $\gamma$ S protein was injected at $5 \mu \mathrm{l} / \mathrm{min}$ for $900 \mathrm{~s}$ to flow cells Fc2 and 4 and $5 \mu \mathrm{g} / \mathrm{ml}$ GST-HRAS-GDP to Fc3. Following GST-HRAS capture on the flow cells, $5 \mu \mathrm{g} / \mathrm{ml}$ anti-RAS scFv Y6-204 was injected at $5 \mu \mathrm{l} / \mathrm{min}$ for $900 \mathrm{~s}$ only to Fc4 until reaching an additional $1500-1800 \mathrm{RU}$, which is theoretically when all GST-HRASGTP $\gamma$ S should be bound to anti-RAS scFv with 1:1 interaction stoichiometry. After completing anti-RAS scFv injection, the sensograms were confirmed to be stable (i.e. anti-RAS scFv was not dissociated from GST-HRAS-GTP $\gamma \mathrm{S}$ on Fc4). The candidate compounds were diluted at $15 \mu \mathrm{M}$ to $2 \mathrm{mM}$ serial concentrations in running buffer with final 5\% DMSO, and a volume of $30 \mu \mathrm{l}$ was injected for $60 \mathrm{~s}$ at a rate of $30 \mu \mathrm{l} / \mathrm{min}$ over all four flow cells of the CM5 chip.

The corresponding kinetic rate constants, $K_{\mathrm{on}}$ and $K_{\text {off }}$, were determined using steady-state analysis of the compounds' binding affinities, assuming 1:1 ligandprotein stoichiometry. The BIAcore evaluation 2.1 software provided by the manufacture was used to analyse the data.

Calculations for the number of response units are required for a 1:1 ratio of compound/protein interaction are shown below.

Protein immobilization: 2500 RU; average fragment 250 approx. Da in size. $R_{\max }=(\mathrm{MWA} / \mathrm{MWL}) \times \mathrm{RL} \times \mathrm{SM}$

MWA is the molecular weight of the analyte in $\mathrm{Da}$

MWL is the molecular weight of the ligand in $\mathrm{Da}$

$\mathrm{RL}$ is the immobilization level in RU

SM is the molar stoichiometry (assume 1:1)

$R \max =250 / 47,500 \times 2500 \times 1$

$R \max =13 \mathrm{RU}$

WaterLOGSY NMR. The waterLOGSY NMR method ${ }^{35}$ was used to measure RAS ligand interaction ${ }^{52}$. WaterLOGSY experiments were conducted at a ${ }^{1} \mathrm{H}$ frequency of $600 \mathrm{MHz}$ using a Bruker Avance spectrometer equipped with a BBI probe. All experiments were conducted at $298 \mathrm{~K}, 3 \mathrm{~mm}$ diameter NMR tubes with a sample final volume of $200 \mu \mathrm{l}$ was used in all experiments. Solutions were buffered using an $\mathrm{H}_{2} \mathrm{O} 10 \mathrm{mM}$ PBS, $5 \mathrm{mM} \mathrm{MgCl}_{2}$ buffer corrected to $\mathrm{pH}$ 7.4. The sample preparation is exemplified as follows, the compound $\left(10 \mu \mathrm{l}\right.$ of a $10 \mathrm{nM}$ solution in DMSO- $\left.d_{6}\right)$ was added to an eppendorf before sequential addition of the $\mathrm{H}_{2} \mathrm{O}$ PBS buffer $(163.6 \mu \mathrm{l}), \mathrm{D}_{2} \mathrm{O}(20 \mu \mathrm{l})$, and protein $(6.4 \mu \mathrm{l}, 311.8 \mu \mathrm{M})$. The resulting solution was spun to ensure full mixing and transferred to a $3 \mathrm{~mm}$ NMR tube before running the experiment. For a competition experiment using $\mathrm{Y} 6-\mathrm{scFv}$ or $\mathrm{VH}$, the preparation was carried out in a similar manner; the compound $(10 \mu \mathrm{l}$ of a $10 \mathrm{mM}$ solution in DMSO- $\left.d_{6}\right)$ was added to an eppendorf before sequential addition of the $\mathrm{H}_{2} \mathrm{O}$ PBS buffer $(146.4 \mu \mathrm{l}), \mathrm{D}_{2} \mathrm{O}(20 \mu \mathrm{l})$, protein $(6.4 \mu \mathrm{l}, 311.8 \mu \mathrm{M})$ and $\mathrm{Y} 6-\mathrm{ScFv}(17.2 \mu \mathrm{l}$, $116.6 \mu \mathrm{M})$ with a ratio of 5.5:1:1. The resulting solution was spun and transferred to a $3 \mathrm{~mm}$ NMR tube before the run. Negative controls (compound alone, without the protein) were prepared in a similar manner, in order to obtain an end volume of $200 \mu \mathrm{l}$.

'H CPMG NMR. Typical experimental parameters for Carr-Purcell-Meiboom-Gill (CPMG) NMR spectroscopy were the following: total echo time, $40 \mathrm{~ms}$; relaxation delay, $2 \mathrm{~s}$; and number of transients, $264^{53}$. The PROJECT-CPMG sequence $\left(90^{\circ} x\right.$ [T-180 $y$-T- $90^{\circ} y-\mathrm{T}-180^{\circ} y$-T $]_{n}$-acq) was applied. Water suppression was achieved by pre-saturation. Prior to Fourier transformation, the data were multiplied with an exponential function with $3-\mathrm{Hz}$ line broadening. The CPMG experiments were conducted at a ${ }^{1} \mathrm{H}$ frequency of $700 \mathrm{MHz}$ using a Bruker Avance with $5 \mathrm{~mm}$ inverse TCI $1 \mathrm{H} / 13 \mathrm{C} / 15 \mathrm{~N}$ cryo-probe. All experiments were conducted at $298 \mathrm{~K}$ and lapsed 128 scans. Furthermore, $3 \mathrm{~mm}$ diameter NMR tubes with a sample volume of $200 \mu \mathrm{l}$ were used in all experiments. Solutions were buffered using a $\mathrm{D}_{2} \mathrm{O}$ PBS buffer corrected to $\mathrm{pH}$ 7.4. The sample preparation is exemplified as follow: with $5 \mu \mathrm{M}$ of protein (PBS pH 7.4, $5 \mathrm{mM} \mathrm{MgCl}_{2}$ ), the compound $(1.1 \mu \mathrm{l}$ of a $10 \mathrm{mM}$ $(55 \mathrm{uM})$ solution in DMSO- $\left.d_{6}\right)$ was added to an eppendorf before sequential addition of the $\mathrm{D}_{2} \mathrm{O} 10 \mathrm{mM}$ PBS, $5 \mathrm{mM} \mathrm{MgCl}_{2}$ buffer adjusted to $\mathrm{pH} 7.4(194.0 \mu \mathrm{l})$ and protein ( $4.9 \mu \mathrm{l}, 205 \mu \mathrm{M}$, the protein is in an $\mathrm{H}_{2} \mathrm{O}$-based buffer for stability reason). The resulting solution was vortexed to be fully mixed and transferred to a $3 \mathrm{~mm}$ NMR tube before the run. Negative controls (compound alone, without the protein) were prepared in a similar manner, in order to obtain an end volume of $200 \mu$ l. CPMG protein titration experiments were carried out at a fixed compound concentration and a variable protein concentration. It was estimated that $55 \mu \mathrm{M}$ solution of the compound was optimum for a good CPMG; protein was titrate increasingly from $0 \mu \mathrm{M}$ until the signal of the compound was undetected in the proton NMR. The integrations of the protons acquired were compared to the reference (compound alone, $0 \mu \mathrm{M}$ of protein) in order to obtain a percentage of decrease for each concentration of protein. Three different proton signals were used and a mean was calculated for each run. Each protein concentration was run in triplicate and a mean was calculated for each concentration. Where error bars are presented, they correspond to mean values \pm SD of experimental repeats. Concentration and percentage of decrease were plotted and $\mathrm{Kd}$ fitting was run on the generated curve using Origin ${ }^{\circledR}$ with the following function: $A^{\star}\left(1 /\left(2^{*} C\right)\right)^{*}((B+$ $\left.x+\mathrm{C})-\operatorname{sqrt}\left(\left((\mathrm{B}+x+\mathrm{C})^{\wedge} 2\right)-\left(4^{*} x^{\star} \mathrm{C}\right)\right)\right)$ where $\mathrm{A}$ is the maximum $\%$ of inhibition (i.e. 100), $\mathrm{B}$ is the $\mathrm{Kd}$ and $\mathrm{C}$ is the concentration of the compound which should not be fixed in the Origin ${ }^{\circledast}$ Equation due to potential variations in compound solubility.

General experimental notes and instrument settings. All solvents and reagents were used as supplied (analytical or HPLC grade) without prior purification. Water was purified by an Elix ${ }^{\oplus} \mathrm{UV}-10$ system. Brine refers to a sat. aq. solution of sodium chloride. In vacuo refers to the use of a rotary evaporator attached to a diaphragm pump. Pet. ether refers to the fraction of petroleum spirit boiling between 30 and $40^{\circ} \mathrm{C}$, unless otherwise stated. Thin layer chromatography was performed on aluminium plates coated with 60 F254 silica. Plates were visualized using UV light $(254 \mathrm{~nm})$ or $1 \%$ aq. $\mathrm{KMnO}_{4}$. Flash column chromatography was performed on Kieselgel $60 \mathrm{M}$ silica in a glass column. NMR spectra were recorded on Bruker Avance spectrometers (AVII400, AVIII 400, AVIIIHD 600 or AVIII 700) in the deuterated solvent stated. The field was locked by external referencing to the relevant deuteron resonance. Chemical shifts $(\delta)$ are reported in parts per million (ppm) referenced to the solvent peak. ${ }^{1} \mathrm{H}$ spectra reported to two decimal places, and ${ }^{13} \mathrm{C}$ spectra reported to one decimal place, and coupling constants $(J)$ are quoted in $\mathrm{Hz}$ (reported to one decimal place). The multiplicity of each signal is indicated by: $s$ (singlet); br. s (broad singlet); d (doublet); $t$ (triplet); $q$ (quartet); $\mathrm{dd}$ (doublet of doublets); td (triplet of doublets); qt (quartet of triplets); or $\mathrm{m}$ (multiplet). Low-resolution mass spectra were recorded on an Agilent 6120 spectrometer from solutions of $\mathrm{MeOH}$. Accurate mass measurements were run on either a Bruker MicroTOF internally calibrated with polyalanine, or a Micromass GCT instrument fitted with a Scientific Glass Instruments BPX5 column $(15 \mathrm{~m} \times$ $0.25 \mathrm{~mm}$ ) using amyl acetate as a lock mass, by the mass spectrometry department of the Chemistry Research Laboratory, University of Oxford, UK.; $\mathrm{m} / \mathrm{z}$ values are reported in Daltons.

Analytical methods. Analysis of products and intermediates was carried out using reverse phase analytical HPLC-MS as well as normal phase analytical LCMS-MS. HPLC analytical methods: AnalpH2_MeOH_4 min: Phenomenex Luna C18 (2) $3 \mu \mathrm{m}, 50 \times 4.6 \mathrm{~mm} ; \mathrm{A}=$ water $+0.1 \%$ formic acid; $\mathrm{B}=\mathrm{MeOH}+0.1 \%$ formic acid; $45^{\circ} \mathrm{C}$; \% B: $0.0 \min 5 \%, 1.0 \min 37.5 \%, 3.0 \min 95 \%$, $3.5 \min 95 \%$, $3.51 \mathrm{~min}$ 5\%, $4.0 \mathrm{~min} 5 \% ; 2.25 \mathrm{ml} / \mathrm{min}$. AnalpH2_MeOH_QC_V1: Phenomenex Gemini NX $\mathrm{C} 185 \mu \mathrm{m}, 150 \times 4.6 \mathrm{~mm} ; \mathrm{A}=$ water $+0.1 \%$ formic acid; $\mathrm{B}=\mathrm{MeOH}+0.1 \%$ formic acid $40^{\circ} \mathrm{C}$; $\mathrm{B}$ : $0.0 \mathrm{~min} 5 \%, 0.5 \mathrm{~min}, 5 \%, 7.5 \mathrm{~min} 95 \%, 10.0 \mathrm{~min} 95 \%, 10.1 \mathrm{~min} 5 \%$ $13.0 \mathrm{~min} 5 \% ; 1.5 \mathrm{ml} / \mathrm{min}$. LCMS Analytical Methods: LCMS Agilent_Gen Method A [100-1000] 6 MIN: Phenomenex Gemini NX C18 $5 \mu \mathrm{m}, 150 \times 4.6 \mathrm{~mm}$; A= water $+\mathrm{pH} 9$ (Ammonium Bicarbonate $10 \mathrm{mM}$ ); $\mathrm{B}=\mathrm{MeOH} ; 40^{\circ} \mathrm{C} ; \% \mathrm{~B}: 0.0 \mathrm{~min}$ $5 \%, 0.50 \mathrm{~min} 5 \%, 7.5 \mathrm{~min} 95 \%, 10.0 \mathrm{~min} 95 \%, 10.1 \mathrm{~min} 5 \%, 13.0 \mathrm{~min} 5 \% ; 1.5 \mathrm{ml} /$ min.

${ }^{1} \mathrm{H}$ and ${ }^{13} \mathrm{C}$ NMR spectra of Abd-2 to Abd-7 and LCMS data for Abd-2, Abd2a, Abd-2b are shown in Supplementary Figs. 9-16. Chemical synthesis protocols are available in Supplementary notes 1-7.

X-ray crystallography. For X-ray diffraction experiments, KRAS ${ }^{\mathrm{Q} 61 \mathrm{H}}-\mathrm{GppNHp}$ crystals were grown at $4{ }^{\circ} \mathrm{C}$ from $1.5 \pm 1.5 \mu \mathrm{l}$ vapour diffusion drops containing $75 \mathrm{mg} / \mathrm{ml}$ KRAS ${ }^{\mathrm{Q}} 61 \mathrm{H}, 8-15 \% \mathrm{w} / \mathrm{v}$ Polyethylene Glycol 3350 and $0.2 \mathrm{M}$ lithium citrate $\mathrm{pH} 5.5$ giving crystal form I. For KRAS ${ }^{\mathrm{G} 12 \mathrm{D}}-\mathrm{GppNHp}$ crystals, drops were prepared by mixing $1.5 \mu \mathrm{l}$ of protein at $45 \mathrm{mg} / \mathrm{ml}$ with $1.5 \mu \mathrm{l}$ of reservoir consisting of $0.1 \mathrm{M}$ TrisCl pH 8.0, 0.2 M NaOAc and 32\% PEG 4000 in 24-well Cryschem sitting-drop plates giving crystal form II. For data collection, crystals were cryoprotected by addition of $20 \%$ glycerol and flash-cooled in liquid nitrogen. For crystal soaking experiments, compounds were added individually $(25-50 \mathrm{mM}$ or saturated solution of compound with a final DMSO concentration of $6-12 \% \mathrm{v} / \mathrm{v}$ ) to the crystallisation buffer. Crystals were then transferred to solution containing compound for a minimum of 5 min. Soaked crystals were cryo-protected with $20 \%$ glycerol and flash-cooled in liquid nitrogen for data collection. In each case, X-ray diffraction data were collected at the Diamond Light Source (DLS, Oxfordshire). The structure of KRAS ${ }^{\mathrm{Q} 1 \mathrm{H}}$ GppNHp-Abd2 to Abd-7 and KRASG12D GppNHpcompound Abd-3 were solved by molecular replacement using Protein Data Bank 
(PDB) codes 3GFT and 4DSU, respectively, with the programme Phaser ${ }^{54,55}$. Structures were refined using REFMAC in the CCP4 suite ${ }^{56}$ and manually corrected using $\operatorname{Cot}^{57}$. Crystal form I (KRAS ${ }^{\mathrm{Q} 61 \mathrm{H}}$ ) has six KRAS molecules in the asymmetric unit, assembled as a hexamer. Electron density maps averaged with sixfold non-crystallographic symmetry (NCS) were used to improve the definition of the bound compounds. Local ncs averaging within REFMAC was used throughout refinement and the final models were validated using PROCHECK molPROBIT and Phenix software packages ${ }^{58,59}$. Figures were created using $\mathrm{PyMOL}^{60}$. Data collection and refinement statistics are summarized in Supplementary Tables 1 and 2.

The PBD codes for the structures presented in this paper are:

KRAS $_{169}{ }^{\text {Q61H }}$ GPPNHP-Abd-2 PDB ID: 5OCO

KRAS $_{169}{ }^{661 \mathrm{H}}$ GPPNHP-Abd-3 PDB ID: 5OCT

KRAS $_{188}$ G12D GPPNHP-Abd-3 PDB ID: 5OCG

KRAS $_{169}{ }^{Q 61 H}$ GPPNHP-Abd-4 PDB ID: 6FA1

KRAS $_{169}{ }^{\text {Q61H }}$ GPPNHP-Abd-5 PDB ID: 6FA2

KRAS $_{169}$ Q61H GPPNHP-Abd-6 PDB ID: 6FA3

KRAS $_{169}{ }^{\text {Q61H }}$ GPPNHP-Abd-7 PDB ID: 6FA4

Kinase panel binding assay. Experiments were performed by Eurofins Pharma Discovery Services. The KinaseProfiler ${ }^{\mathrm{Tw}}$ assay protocol guide can be downloaded from their website: www.eurofins.com/discoveryservices. The guide contains information on the buffer conditions, substrate and reference inhibitor blank used for each kinase.

Tissue culture assays. HEK293T human embryonic kidney cells were grown in DMEM medium (Life Technologies) supplemented with 10\% FBS (Sigma) and 1\% Penicillin/Streptomycin (Life Technologies). Cells were grown at $37^{\circ} \mathrm{C}$ with $5 \%$ $\mathrm{CO}_{2}$. Cells were obtained for the American Tissue Culture Collection except HEK293T that was obtained locally.

BRET2 cell assay. The BRET assay was carried out as described elsewhere ${ }^{42}$. A total of 650,000 HEK293T were seeded in each well of a six well plate. Approximately, $24 \mathrm{~h}$ later, cells were transfected with an appropriated BRET-based RAS biosensor (i.e. RAS-effector) using Lipofectamine 2000 transfection reagent (Thermo-Fisher). Cells were detached $24 \mathrm{~h}$ later and washed with PBS and seeded in a white 96 well plate (clear bottom, PerkinElmer, cat\#6005181) in OptiMEM no phenol red medium (Life Technologies) complemented with $4 \%$ FBS. Cells were left for $4 \mathrm{~h}$ at $37^{\circ} \mathrm{C}$ before adding compounds. Stock compounds were held at $10 \mathrm{mM}$ in $100 \%$ DMSO and diluted in OptiMEM no red phenol + 4\% FBS to reach $10 \mathrm{X}$ the final concentration (2\% DMSO for each concentration). The final concentrations in the cells were $0,5,10$ and $20 \mu \mathrm{M}$ (therefore the intermediate 10X concentrations were $0,50,100$ and $200 \mu \mathrm{M}$. Furthermore, $10 \mu \mathrm{l}$ of $10 \mathrm{X}$ compounds were added in each well of the 96 well plate to $0,5,10$ and $20 \mu \mathrm{M}$ final concentrations (with final 0.2\% DMSO each). Quadruplicates were performed for each point. Cells were left for an additional $20 \mathrm{~h}$ at $37^{\circ} \mathrm{C}$ before the BRET2 signal reading directly after addition of Coelenterazine $400 \mathrm{a}$ substrate $(10 \mu \mathrm{M}$ final) to cells (Cayman Chemicals, cat\#16157). BRET2 reading was carried out on an Envision instrument (2103 Multilabel Reader, PerkinElmer) with the BRET2 Dual Emission optical module $(515 \mathrm{~nm} \pm 30$ and $410 \mathrm{~nm} \pm 80$; PerkinElmer $)$.

Biomarker phosphorylation assay. A total of 450,000 DLD1 or 640,000 H358 cells were seeded per well of a six well plate. Approximately, $20 \mathrm{~h}$ later, the medium was removed, the cells washed twice with PBS and DMEM without FBS was added and left for $24 \mathrm{~h}$. The medium was removed and $2 \mathrm{ml}$ of DMEM no FBS was added with the appropriate concentration of compound (DMSO, 2, 5, 10 or $20 \mu \mathrm{M}$ ) for $3 \mathrm{~h}$. Cells were stimulated with EGF $(50 \mathrm{ng} / \mathrm{ml})$ for $10 \mathrm{~min}$, washed once with PBS and directly lysed in SDS-Tris buffer (1\% SDS, $10 \mathrm{mM}$ Tris-HCl pH 7.4) supplemented with protease inhibitors (Sigma) and phosphatase inhibitors (ThermoFisher). Cell lysates were sonicated with a Branson Sonifier and the protein concentrations determined by using the Pierce BCA protein assay kit (Thermo-Fisher). Furthermore, $10 \mu \mathrm{g}$ of protein were resolved on 10 or $12.5 \%$ SDS-PAGE and subsequently transferred onto a PVDF membrane (GE). The membrane was blocked (with 10\% non-fat milk (Sigma) or 10\% BSA (Sigma) in TBS-0.1\% Tween20) and incubated overnight with primary antibody at $4{ }^{\circ} \mathrm{C}$. Primary antibodies include anti-phospho-p44/22 MAPK (ERK1/2) (1/4000, CST, Cat\#9101S), anti-p44/42 MAPK (total ERK1/2) (1/1000, CST, Cat\#9102S), anti-phospho-AKT S473 (1/1000, CST, Cat\#4058S), anti-AKT (1/1000, CST, Cat\#9272S), anticyclophilin B (1/1000, Abcam, Cat\#178397). After washing, the membrane was incubated with an anti-rabbit IgG HRP-linked (1/3000, CST, Cat\#7074S) secondary antibody for $1 \mathrm{~h}$ at room temperature. The membrane was washed with TBS- $0.1 \%$ Tween and developed using Pierce ECL Western Blotting Substrate (ThermoFisher) and CL-XPosure films (Thermo-Fisher). Uncropped Western blots are shown in Supplementary Fig. 17.

Cell viability assays. Cancer cell lines were in seeded in ViewPlates-96 microplates (PerkinElmer). DLD-1 cells were plated at 10,000 cells per well and HT1080 cells at 7500 cells per well and cultured in DMEM, high glucose, GlutaMAX media containing $10 \% \mathrm{FBS}$ at $37^{\circ} \mathrm{C}$ in $5 \% \mathrm{CO}_{2}$ atmosphere. Cells were cultured overnight and the compounds (dissolved in DMSO and diluted to $0.2 \%$ DMSO) were added to the cells at concentrations ranging from 0 to $20 \mu \mathrm{M}$. The cells were incubated under standard culture conditions for either 24,48 or $72 \mathrm{~h}$. Cell viability was as quantitated using the CellTiterGlo Luminescent Cell Viability Assay (Promega) according to the manufacturer's instructions to measure ATP generated by metabolically active cells. Luminescent signals were measured using an Envision 2103 Multilabel Microplate Reader (PerkinElmer). The luminescence signals obtained from the compound-treated cells were normalized against the signal for DMSO-only treated cells. The IC50 values, calculated from the 48 and $72 \mathrm{~h}$ CellTiterGlo data, were generated by non-linear regression using the software GraphPad Prism 7.00 for windows (GraphPad Inc).

Data availability. Crystallographic data have been deposited in the PDB, accession codes: 5OCO, 5OCT, 5OCG, 6FA1, 6FA2, 6FA3, 6FA4. Other relevant data of this study are included within the article and its Supplementary Information. All data supporting the findings of this study are also available from the corresponding author upon reasonable request.

Received: 19 April 2018 Accepted: 18 July 2018

Published online: 09 August 2018

\section{References}

1. Arkin, M. R., Tang, Y. \& Wells, J. A. Small-molecule inhibitors of proteinprotein interactions: progressing toward the reality. Chem. Biol. 21, 1102-1114 (2014).

2. Biocca, S. \& Cattaneo, A. Intracellular immunization: antibody targeting to subcellular compartments. Trends Cell Biol. 5, 248-252 (1995).

3. Tanaka, T., Williams, R. L. \& Rabbitts, T. H. Tumour prevention by a single antibody domain targeting the interaction of signal transduction proteins with RAS. EMBO J. 26, 3250-3259 (2007).

4. Cochet, O. et al. Intracellular expression of an antibody fragment-neutralizing p21 ras promotes tumor regression. Cancer Res. 58, 1170-1176 (1998).

5. Tanaka, T. \& Rabbitts, T. H. Interfering with protein-protein interactions: potential for cancer therapy. Cell Cycle 7, 1569-1574 (2008).

6. Erijman, A. \& Shifman, J. M. RAS/effector interactions from structural and biophysical perspective. Mini Rev. Med. Chem. 16, 370-375 (2016).

7. Reverdatto, S., Burz, D. S. \& Shekhtman, A. Peptide aptamers: development and applications. Curr. Top. Med. Chem. 15, 1082-1101 (2015).

8. Cheng, A. C. et al. Structure-based maximal affinity model predicts smallmolecule druggability. Nat. Biotechnol. 25, 71-75 (2007).

9. Smith, R. D. et al. Exploring protein-ligand recognition with binding MOAD J. Mol. Graph. Model. 24, 414-425 (2006).

10. Hopkins, A. L. \& Groom, C. R. The druggable genome. Nat. Rev. Drug. Discov 1, 727-730 (2002)

11. Scott, D. E., Bayly, A. R., Abell, C. \& Skidmore, J. Small molecules, big targets: drug discovery faces the protein-protein interaction challenge. Nat. Rev. Drug. Discov. 15, 533-550 (2016).

12. Rognan, D. Rational design of protein-protein interaction inhibitors. Medchemcomm 6, 51-60 (2015)

13. Tanaka, T., Lobato, M. N. \& Rabbitts, T. H. Single domain intracellular antibodies: a minimal fragment for direct in vivo selection of antigen-specific intrabodies. J. Mol. Biol. 331, 1109-1120 (2003).

14. Lo Conte, L., Chothia, C. \& Janin, J. The atomic structure of protein-protein recognition sites. J. Mol. Biol. 285, 2177-2198 (1999).

15. Ward, E. S., Gussow, D., Griffiths, A. D., Jones, P. T. \& Winter, G. Binding activities of a repertoire of single immunoglobulin variable domains secreted from Escherichia coli. Nature 341, 544-546 (1989).

16. Doak, B. C., Zheng, J., Dobritzsch, D. \& Kihlberg, J. How beyond rule of 5 drugs and clinical candidates bind to their targets. J. Med. Chem. 59, 2312-2327 (2016)

17. Lipinski, C. A., Lombardo, F., Dominy, B. W. \& Feeney, P. J. Experimental and computational approaches to estimate solubility and permeability in drug discovery and development settings. Adv. Drug Deliv. Rev. 46, 3-26 (2001).

18. Prior, I. A., Lewis, P. D. \& Mattos, C. A comprehensive survey of Ras mutations in cancer. Cancer Res. 72, 2457-2467 (2012).

19. Simanshu, D. K., Nissley, D. V. \& McCormick, F. RAS proteins and their regulators in human disease. Cell 170, 17-33 (2017).

20. Alexandrov, L. B. et al. Signatures of mutational processes in human cancer Nature 500, 415-421 (2013).

21. Upadhyaya, P. et al. Inhibition of Ras signaling by blocking Ras-effector interactions with cyclic peptides. Angew. Chem. Int. Ed. Engl. 54, 7602-7606 (2015)

22. Shin, S. M. et al. Antibody targeting intracellular oncogenic Ras mutants exerts anti-tumour effects after systemic administration. Nat. Commun. 8, 15090 (2017). 
23. Werge, T. M., Biocca, S. \& Cattaneo, A. Intracellular immunization. Cloning and intracellular expression of a monoclonal antibody to the p21ras protein. FEBS Lett. 274, 193-198 (1990).

24. Maurer, T. et al. Small-molecule ligands bind to a distinct pocket in Ras and inhibit SOS-mediated nucleotide exchange activity. Proc. Natl. Acad. Sci. USA 109, 5299-5304 (2012).

25. Sun, Q. et al. Discovery of small molecules that bind to K-Ras and inhibit Sosmediated activation. Angew. Chem. Int. Ed. Engl. 51, 6140-6143 (2012).

26. Ostrem, J. M., Peters, U., Sos, M. L., Wells, J. A. \& Shokat, K. M. K-Ras(G12C) inhibitors allosterically control GTP affinity and effector interactions. Nature 503, 548-551 (2013).

27. Burns, M. C. et al. Approach for targeting Ras with small molecules that activate SOS-mediated nucleotide exchange. Proc. Natl. Acad. Sci. USA 111, 3401-3406 (2014).

28. Winter, J. J. et al. Small molecule binding sites on the Ras:SOS complex can be exploited for inhibition of Ras activation. J. Med. Chem. 58, 2265-2274 (2015).

29. Lito, P., Solomon, M., Li, L. S., Hansen, R. \& Rosen, N. Allele-specific inhibitors inactivate mutant KRAS G12C by a trapping mechanism. Science 351, 604-608 (2016).

30. Patricelli, M. P. et al. Selective inhibition of oncogenic KRAS output with small molecules targeting the inactive state. Cancer Discov. 6, 316-329 (2016).

31. Athuluri-Divakar, S. K. et al. A small molecule RAS-mimetic disrupts RAS association with effector proteins to block signaling. Cell 165, 643-655 (2016).

32. Welsch, M. E. et al. Multivalent small-molecule Pan-RAS inhibitors. Cell 168, 878-889 (2017). e829.

33. Visintin, M., Tse, E., Axelson, H., Rabbitts, T. H. \& Cattaneo, A. Selection of antibodies for intracellular function using a two-hybrid in vivo system. Proc. Natl. Acad. Sci. USA 96, 11723-11728 (1999).

34. Tanaka, T. \& Rabbitts, T. H. Protocol for the selection of single-domain antibody fragments by third generation intracellular antibody capture. Nat. Protoc. 5, 67-92 (2010).

35. Tanaka, T. \& Rabbitts, T. H. Interfering with RAS-effector protein interactions prevent RAS-dependent tumour initiation and causes stop-start control of cancer growth. Oncogene 29, 6064-6070 (2010).

36. Tanaka, T. \& Rabbitts, T. H. Intrabodies based on intracellular capture frameworks that bind the RAS protein with high affinity and impair oncogenic transformation. EMBO J. 22, 1025-1035 (2003).

37. Meyer, B. \& Peters, T. NMR spectroscopy techniques for screening and identifying ligand binding to protein receptors. Angew. Chem. Int. Ed. Engl. 42, 864-890 (2003).

38. Dalvit, C., Fogliatto, G., Stewart, A., Veronesi, M. \& Stockman, B. WaterLOGSY as a method for primary NMR screening: practical aspects and range of applicability. J. Biomol. NMR 21, 349-359 (2001).

39. Grant, B. J. et al. Novel allosteric sites on Ras for lead generation. PLoS One 6, e25711 (2011).

40. Kleckner, I. R. \& Foster, M. P. An introduction to NMR-based approaches for measuring protein dynamics. Biochim. Biophys. Acta 1814, 942-968 (2011).

41. Claridge, T. D. W. in High-Resolution NMR Techniques in Organic Chemistry (Third Edition) 421-455 (Elsevier, 2016).

42. Bery, N. et al. BRET-based RAS biosensors that show a novel small molecule is an inhibitor of RAS-effector protein-protein interactions. eLife 7, e37122 (2018).

43. Kirchhofer, A. et al. Modulation of protein properties in living cells using nanobodies. Nat. Struct. Mol. Biol. 17, 133-138 (2010).

44. Revets, H., De Baetselier, P. \& Muyldermans, S. Nanobodies as novel agents for cancer therapy. Expert. Opin. Biol. Ther. 5, 111-124 (2005).

45. Rabbitts, T. H. \& Stocks, M. R. Chromosomal translocation products engender new intracellular therapeutic technologies. Nat. Med. 9, 383-386 (2003).

46. Fan, X. et al. A homogeneous time-resolved fluorescence-based highthroughput screening for discovery of inhibitors of Nef-sdAb19 interaction. Int. J. Oncol. 47, 1485-1493 (2015).

47. Waldmann, H. et al. Sulindac-derived Ras pathway inhibitors target the RasRaf interaction and downstream effectors in the Ras pathway. Angew. Chem. Int. Ed. Engl. 43, 454-458 (2004).

48. Gonzalez-Perez, V. et al. Genetic and functional characterization of putative Ras/Raf interaction inhibitors in C. elegans and mammalian cells. J. Mol. Signal. 5, 2 (2010).

49. Johnstone, S. \& Albert, J. S. Pharmacological property optimization for allosteric ligands: A medicinal chemistry perspective. Bioorg. Med. Chem. Lett. 27, 2239-2258 (2017).

50. Lawson, A. D. G., MacCoss, M. \& Heer, J. P. Importance of rigidity in designing small molecule drugs To tackle protein-protein interactions (PPIs) through stabilization of desired conformers. J. Med. Chem. 61, 4283-4289 (2017).

51. Hermann, C., Horn, G., Spaargaren, M. \& Wittinghofer, A. Differential interaction of the ras family GTP-binding proteins H-RAs, Rap1A, and R-Ras with the putative effector molecules Raf kinase and Ral-guanine nucleotide exchange factor. J. Biol. Chem. 271, 6794-6800 (1996).

52. Huang, R., Bonnichon, A., Claridge, T. D. \& Leung, I. K. Protein-ligand binding affinity determination by the waterLOGSY method: an optimised approach considering ligand rebinding. Sci. Rep. 7, 43727 (2017).

53. Abboud, M. I. et al. Interaction of avibactam with class B metallo-betalactamases. Antimicrob. Agents Chemother. (Bethesda) 60, 5655-5662 (2016).

54. McCoy, A. J. Solving structures of protein complexes by molecular replacement with phaser. Acta Crystallogr. D. Biol. Crystallogr. 63, 32-41 (2007).

55. McCoy, A. J. et al. Phaser crystallographic software. J. Appl. Crystallogr. 40, 658-674 (2007).

56. Murshudov, G. N., Vagin, A. A. \& Dodson, E. J. Refinement of macromolecular structures by the maximum-likelihood method. Acta Crystallogr. D. Biol. Crystallogr. 53, 240-255 (1997).

57. Emsley, P., Lohkamp, B., Scott, W. G. \& Cowtan, K. Features and development of Coot. Acta Crystallogr. D. Biol. Crystallogr. 66, 486-501 (2010).

58. Laskowski, R. A., MacArthur, M. W., Moss, D. S. \& Thornton, J. M. PROCHECK: a program to check the stereochemical quality of protein stuctures. J. App. Cryst. 26, 283-291 (1993).

59. Adams, P. D. et al. PHENIX: a comprehensive Python-based system for macromolecular structure solution. Acta Crystallogr. D. Biol. Crystallogr. 66 213-221 (2010).

60. DeLano, W. L. The PyMOL Molecular Graphics System, Version 1.1. (2002).

\section{Acknowledgements}

This work was supported by grants from the Wellcome Trust (100842/Z/12/Z) and (099246/Z/12/Z), the Medical Research Council (MR/J000612/1) and Bloodwise (12051). We are grateful to Dr Martin Drysdale and the CRUK Beatson Institute Drug Discovery Group for providing the chemical fragment library and to Professor Andy Hamilton for discussions on the project. We would like to thank Prof. Tim D.W. Claridge for help and crucial advice on NMR techniques. We also like to thank Dr. Tim Fagge for very helpful advice on the use of the Biacore T100 and T200. We acknowledge the beamline staff at stations I02, I03 and I04-1 at the Diamond Light Source, UK (proposals mx9306 and mx13456) and the European Synchrotron Radiation Facility at stations ID30A-1 and ID30A-3 and we would like to thank Matthew Bowler and Edward Lowe for assistance during X-ray diffraction experiments. We also wish to thank Drs. Stuart Crosby, Jonathan Dunn, Robert Freem, Traore Tenin and Sophie Williams for the chemistry. We are also grateful to Drs. Trevor Perrior, Alan Naylor and Graham Showell for input and advice.

\section{Author contributions}

Originator of project: T.R. Conducted experiments: C.Q., A.C., T.T., D.P., N.B., L.L., A.M., C.B., H.T., M.E. Contributed new reagents or analytic tools: N.F.F. Performed data analysis: C.Q., A.C., N.B., T.T., D.P., C.B., L.L., P.F., M.E., N.F.F., A.R., S.C., S.P., T.R. Contributed to the writing of the manuscript: All authors.

\section{Additional information}

Supplementary Information accompanies this paper at https://doi.org/10.1038/s41467018-05707-2.

Competing interests: The authors declare no competing interests.

Reprints and permission information is available online at http://npg.nature.com/ reprintsandpermissions/

Publisher's note: Springer Nature remains neutral with regard to jurisdictional claims in published maps and institutional affiliations.

cc (i) Open Access This article is licensed under a Creative Commons Attribution 4.0 International License, which permits use, sharing, adaptation, distribution and reproduction in any medium or format, as long as you give appropriate credit to the original author(s) and the source, provide a link to the Creative Commons license, and indicate if changes were made. The images or other third party material in this article are included in the article's Creative Commons license, unless indicated otherwise in a credit line to the material. If material is not included in the article's Creative Commons license and your intended use is not permitted by statutory regulation or exceeds the permitted use, you will need to obtain permission directly from the copyright holder. To view a copy of this license, visit http://creativecommons.org/ licenses/by/4.0/.

(c) The Author(s) 2018 